\title{
Pt-Decorated TiO2 Materials Supported on Carbon : Increasing Activities and Stabilities toward the ORR by Tuning the Pt Loading
}

\section{Barbosa, Eduardo C. M.}

2019-08

Barbosa , E C M , Parreira , L S , de Freitas , I C , Aveiro , L R , de Oliveira , D C , dos Santos , M C \& Camargo , P H C 2019 , ' Pt-Decorated TiO2 Materials Supported on Carbon : Increasing Activities and Stabilities toward the ORR by Tuning the Pt Loading ', Acs applied energy materials, vol. 2 , no. 8 , pp. 5759-5768 . https://doi.org/10.1021/acsaem.9b00879

http://hdl.handle.net/10138/321548

https://doi.org/10.1021/acsaem.9b00879

acceptedVersion

Downloaded from Helda, University of Helsinki institutional repository.

This is an electronic reprint of the original article.

This reprint may differ from the original in pagination and typographic detail.

Please cite the original version. 
1 Pt-decorated $\mathrm{TiO}_{2}$ materials supported on carbon: increasing activities and stabilities towards the ORR by tuning the Pt loading

Eduardo C. M. Barbosa ${ }^{a,+}$, Luanna S. Parreira ${ }^{a,+}$, Isabel C. de Freitas ${ }^{a}$, Luci R. Aveiro ${ }^{b}$, Daniela

C. de Oliveirac , Mauro C. dos Santos ${ }^{b}$, and Pedro H. C. Camargo ${ }^{a, d *}$

a Departamento de Química Fundamental, Instituto de Química, Universidade de São Paulo,

8 Av. Prof. Lineu Prestes, 748, 05508-000 São Paulo, SP, Brazil

9 b Laboratório de Eletroquímica e Materiais Nanostruturados - Centro de Ciências Naturais e

10 Humanas, Universidade Federal do ABC, Rua Santa Adélia, 166, 09210-170, Santo André, SP,

11 Brazil

$12{ }^{\mathrm{C}}$ Centro Nacional de Pesquisa em Energia e Materiais, Laboratório Nacional de Luz

13 Síncrotron, 13083-970, Campinas, SP, Brazil

$14{ }^{d}$ Department of Chemistry, University of Helsinki, A.I. Virtasen aukio 1, Helsinki, Finland

15

16

*Corresponding author: Email: pedro.camargo@helsinki.fi

17

+ These authors contributed equally to this article

18 
3 Pt nanoparticles (Pt NPs) supported on carbon have been widely employed as electrocatalysts

4 towards the oxygen reduction kinetics. The development of more efficient electrocatalysts

5 that enable one to reduce or even not require the use of $\mathrm{Pt}$ is a central challenge. In addition

6 to the control over Pt NPs physical and chemical features, metal-support interactions can be

7 employed to enhance activities via the generation and exposure of surface-active sites. In this

8 context, we report herein the development of electrocatalysts composed of Pt NPs supported

9 on $\mathrm{TiO}_{2}$ microspheres, that were subsequently impregnated onto carbon. We have found that

10 by optimizing the loading of $\mathrm{Pt}$ at the $\mathrm{TiO} 2$ surface, the electrocatalytic activity towards the

11 ORR could be improved compared to the commercial Pt/C (E-TEK) material, even at lower Pt

12 loadings. The enhancement in activities could be assigned to the balance between Pt loading

13 and generation of reactive surface sites, such as adsorbed oxygenated species. Moreover, the

14 utilization of $\mathrm{TiO}_{2}$ as support enabled improved stabilities relative to $\mathrm{Pt} / \mathrm{C}$ (E-TEK). We believe

15 that the results described herein may inspire the development of electrocatalysts for the ORR

16 with improved activities and stabilities.

17

18 Keywords: Oxygen reduction reaction, electrocatalysis, Pt nanoparticles, $\mathrm{TiO}_{2}$, metal-support

19 interactions, controlled synthesis 

membrane (PEM) fuel cells and contributes to the energy production of these devices. ${ }^{1,2}$ Due to its sluggish kinetics, the ORR requires electrocatalysts based on platinum nanoparticles (Pt NPs) supported on high surface area materials., ${ }^{3,4}$ However, due to the high costs and low

7 abundance of $\mathrm{Pt}$, the reduction in Pt loading or even developing Pt-free electrocatalysts represents an important challenge. ${ }^{5,6}$ Recently, significant progress has been achieved in

9 performance through the control over the Pt shape, size, composition (alloys and

10 multimetallic systems), and structure (Pt-based nanostructures with hollow interiors). ${ }^{3,7}$

11 Nevertheless, further understanding of the electrocatalytic enhancements are still required

12 to meet cost/energy demands and enable the widespread application of these devices..$^{8,9}$

In addition to the NPs physical and chemical parameters, the optimization over

14 metal-support interactions can be employed to maximize electrocatalytic performance due

15 to metal-support interactions such as the generation of surface reactive sites. ${ }^{10-12}$ In the

16 context of the ORR, most supports are comprised of conductive carbon nanomaterials. 6,13

17 However, carbon supports usually corrode to form carbon dioxide, leading to the collapse and

18 agglomeration of Pt NPs and thus the loss of activity in the longer term. ${ }^{14,15}$ Therefore, the

19 utilization of other supports is promising to improve both the stability and performances.

20 Among the several promising materials as supports, titanium dioxide $\left(\mathrm{TiO}_{2}\right)$ is resistant to

21 corrosion, presents a low cost, is commercially available, and several protocols for the 
1 synthesis have been reported. ${ }^{16,17}$ However, a major drawback is that the $\mathrm{TiO}_{2}$ electrical

2 conductivity must be enhanced to be used as a support material. In this case, hybrid materials

3 comprised of $\mathrm{TiO}_{2}$ and carbon have been proposed. This system combines the attractive

4 features of both materials. Nevertheless, a deeper understanding of the effect of $\mathrm{TiO}_{2}$ as

5 support over the detected ORR activities and stabilities is required. ${ }^{16,18}$

In this paper, we developed electrocatalysts composed of Pt NPs supported on $\mathrm{TiO}_{2}$

7 microspheres, that were subsequently impregnated into conductive carbon (Vulcan) as model

8 systems to investigate the effect of the Pt loading on $\mathrm{TiO}_{2}$ over the ORR activities and stability.

9 The effect of $\mathrm{Pt}$ loading at the $\mathrm{TiO}_{2}$ surface, as well as the $\mathrm{Pt} / \mathrm{TiO}_{2}$ loading on carbon, was

10 investigated and benchmarked against the commercial Pt/C (E-TEK) material. We found that

11 the loading of $\mathrm{Pt}$ and $\mathrm{TiO}_{2}$ played a central role over the exposure of reactive sites and thus

12 to the ORR activities. This effect could be related to the generation of surface reactive groups,

13 such as adsorbed oxygenated species, as a result of the optimized metal-support interactions.

15 Experimental

Materials and Instrumentation

$\mathrm{H}_{2} \mathrm{PtCl}_{6} \cdot 6 \mathrm{H}_{2} \mathrm{O}$ (Chloroplatinic acid hexahydrate, Sigma-Aldrich), PVP

19 (polyvinylpyrrolidone, Sigma-Aldrich, MW $55000 \mathrm{~g} \mathrm{~mol}^{-1}$ ), EG (ethylene glycol, 99.5\%, Synth),

$20 \mathrm{C}_{3} \mathrm{H}_{6} \mathrm{O}$ (acetone, 99.5\%, Synth), $\mathrm{C}_{2} \mathrm{H}_{4} \mathrm{O}_{2}$ (acetic acid, 99.7\%, Vetec), $\mathrm{C}_{6} \mathrm{H}_{8} \mathrm{O}_{6}$ (ascorbic acid,

$2199.0 \%$, Sigma-Aldrich), $\mathrm{Ti}(\mathrm{OBu})_{4}$ (titanium butoxide, 97\%, Sigma-Aldrich), Vulcan XC-72 
1 Carbon $\left(\right.$ Cabot $\left.^{\circledR}\right), \mathrm{H}_{2} \mathrm{SO}_{4}$ (sulfuric acid, 70\%, P.A. Synth), Nafion ${ }^{\circledR}$ (5 wt.\%, Fluka), and Pt/C E-

2 TEK 10 wt.\% were used as received. All chemicals were analytical grade reagents and were

3 used without further purification. Deionized water (18.2 M $)$ ) was used throughout the

4 experiments. Scanning electron microscopy (SEM) images were obtained using a JEOL microscope

6 FEG-SEM JSM 6330F operated at $5 \mathrm{kV}$. The samples were prepared by drop-casting an

7 aqueous suspension of the nanostructures on a Si wafer followed by drying under ambient conditions. Size distribution profile was determined by individually measuring the size of 200

9 particles from SEM images. Transmission electron microscopy (HRTEM) images were obtained

10 using a Tecnai FEl G20 operated at $200 \mathrm{kV}$. Samples were prepared by drop casting an

11 alcoholic suspension of each particle in a carbon-coated copper grid followed by drying under

12 ambient conditions. The X-ray photoelectron spectroscopy (XPS) analyses were performed using a

14 SPECSLAB II (Phoibos-Hsa 3500 150, 9 channeltrons) SPECS spectrometer, with an Al Ka 15 source $(E=1486.6 \mathrm{eV})$ working at $12 \mathrm{kV}$, Epass $=40 \mathrm{eV}$, with $0.2 \mathrm{eV}$ energy step. The 16 synthesized electrocatalysts were kept on stainless steel sample-holders and transported 17 under inert atmosphere into the pre-chamber of the XPS staying under vacuum for 2 hours.

18 The residual pressure in the analysis chamber was of approximately $1 \times 10^{-9}$ Torr. The binding 19 energies (BE) of Pt 4f, Ti 2p, O 1s, and C 1s spectral peaks were adjusted using the $\mathrm{C}$ 1s peak 20 as reference, placed at $284.5 \mathrm{eV}$, providing accuracy within $\pm 0.2 \mathrm{eV}$. 
2 CuK $\alpha$ radiation of $1.5406 \AA$ and the diffraction patterns were acquired in the range of $2 \theta=10$

$3-80^{\circ}$ with a $1^{\circ} \min -1$ scanning speed. Pt atomic percentages were measured by inductively coupled plasma optical emission spectrometry (ICP-OES) using a Spectro Arcos equipment at IQ-USP analytical center facilities. Samples were prepared by digesting them using aqua regia at reflux for 2 hours at $100^{\circ} \mathrm{C}$. After digestion, samples were diluted using distilled water.

Synthesis of $\mathrm{TiO}_{2}$ colloidal spheres

The synthesis followed a previously reported procedure. ${ }^{19,20}$ Typically, $\mathrm{Ti}(\mathrm{OBu})_{4}(4$ $\mathrm{mL}$ ) were added dropwise to ethylene glycol $(90 \mathrm{~mL})$ and kept under vigorous stirring at room temperature for 8 hours. This mixture was then quickly poured into a mixture containing acetone $(400 \mathrm{~mL})$, deionized water $(5 \mathrm{~mL})$, and acetic acid $(2 \mathrm{~mL})$. Subsequently, the mixture was kept under stirring at room temperature for 2 hours followed by aging for 3 more hours.

14 At this stage, titanium glycolate microspheres were formed. They were washed and isolated

15 by successive rounds of centrifugation, removal of the supernatant, and re-suspension in

16 ethanol. In the next step, deionized water $(50 \mathrm{~mL})$ was added to the solid material comprising

17 titanium glycolate microspheres, the materials were re-suspended, and this mixture was kept

18 under stirring at $70{ }^{\circ} \mathrm{C}$ for 8 hours to produce TiO2 colloidal spheres. This material was washed

19 and isolated by successive rounds of centrifugation, removal of the supernatant, and resuspension with water and ethanol. The $\mathrm{TiO}_{2}$ colloidal spheres were then resuspended in

21 deionized water $(500 \mathrm{~mL})$. 
Synthesis of Pt/TiO 2 via Pt seeded growth $\mathrm{TiO}_{2}$ microspheres $(12 \mathrm{mg})$ suspended in deionized water $(6 \mathrm{~mL})$ were added to a mixture containing deionized water $(12 \mathrm{~mL})$, ascorbic acid $(12 \mathrm{mg})$, and PVP (70 mg). This orange mixture was kept under stirring for 10 minutes at $90{ }^{\circ} \mathrm{C}$ and at this point, $\mathrm{PtCl}_{6}{ }^{2-}{ }_{\text {(aq) }}(6$ $\mathrm{mL}, 3.0 \mathrm{mmol} \mathrm{L}^{-1}$ ) was quickly added to the mixture, which after 10 minutes produced a change in color to black as a result of $\mathrm{Pt}$ deposition at the $\mathrm{TiO}_{2}$ surface. The reaction was allowed to proceed for other 30 minutes at $90^{\circ} \mathrm{C}$. This was the first reduction step, the material obtained at this stage was denoted $\mathrm{Pt}_{/} \mathrm{TiO}_{2}-1$, in which the number 1 refers to one

10 Pt deposition step. A second reduction step was performed by adding more $\mathrm{PtCl}_{6}{ }^{2-}$ (aq) solution

$11\left(6 \mathrm{~mL}, 3.0 \mathrm{mmol} \mathrm{L}^{-1}\right)$ to the reaction mixture obtained at the end of the first reduction step,

12 followed by stirring at $90^{\circ} \mathrm{C}$ for other $30 \mathrm{~min}$. Similarly, a third reduction step was carried out

13 by adding more $\mathrm{PtCl}_{6}{ }^{2-}{ }_{(\mathrm{aq})}$ solution $\left(6 \mathrm{~mL}, 3.0 \mathrm{mmol} \mathrm{L}^{-1}\right)$ to the reaction mixture obtained at the 14 end of the second reduction step, followed by stirring at $90{ }^{\circ} \mathrm{C}$ for another $30 \mathrm{~min}$. As 15 described in the first deposition step, the solids that were obtained after the second and third 16 reduction steps were denoted $\mathrm{Pt} / \mathrm{TiO}_{2}-2$ and $\mathrm{Pt} / \mathrm{TiO}_{2}-3$, respectively. These materials were

17 isolated by stopping the reaction at the end of each corresponding reduction step. In all cases,

18 the products were harvested by centrifugation, washed several times with water and ethanol,

19 and re-suspended in water for further use. These samples were dried and weighed for ICP-

20 OES analyses. 

support for the nanomaterials. The supports were added to aqueous suspensions containing $5 \mathrm{mg}$ of each material and left under vigorous magnetic stirring at $110^{\circ} \mathrm{C}$ until dry.

Electrochemical studies

The electrochemical experiments were performed at $25^{\circ} \mathrm{C}$ in an electrochemical three-electrode cell with $\mathrm{H}_{2} \mathrm{SO}_{4}\left(80 \mathrm{~mL}, 0.5 \mathrm{~mol} \mathrm{~L}^{-1}\right)$ as support electrolyte using a potentiostat/galvanostat PGSTAT model $302 \mathrm{~N}\left(\right.$ Autolab $\left.^{\circledR}\right)$ coupled to a rotating ring-disk electrode accessory (Pine ${ }^{\circledR}$ ) and controlled by the Nova 10.1 software. The counter electrode was a platinum rod, while an $\mathrm{Ag} / \mathrm{AgCl}$ electrode $\left(\right.$ Analyzer $^{\circledR}$ ) was used as reference. The work electrode was a rotating ring-disk electrode consisting of a glassy carbon disk $\left(0.196 \mathrm{~cm}^{2}\right)$ and platinum ring $\left(0.037 \mathrm{~cm}^{2}\right)$ with the collection factor of 0.37 . After thoroughly characterizing

16 the catalysts, a suspension of each material was prepared in milli-Q water in order to deposit

17 them onto the electrode. An ink was prepared using $1 \mathrm{mg}$ of electrocatalyst and $1 \mathrm{~mL}$ of

18 ultrapure water (Milli Q system, $18.2 \mathrm{~m} \Omega \mathrm{cm}^{-1}$ ) sonicated for 30 minutes. The glassy carbon

19 disk surface was covered by a drop of $20 \mathrm{uL}$ of the electrocatalytic ink and dried under $\mathrm{N}_{2}$ flux.

20 Subsequently, $20 \mu \mathrm{L}$ of a 1:100 solution of $\mathrm{Nafion}^{\circledR}$ and ultrapure water were dropped onto 
1 the material, and then further dried under $\mathrm{N}_{2}$ flux at room temperature. The electrocatalysts

2 were then further characterized regarding their electrocatalytic properties. For CO stripping measurements, carbon monoxide was adsorbed on a $20 \mathrm{mV}$

4 polarized electrode, during 5 minutes, immersed in an $\mathrm{H}_{2} \mathrm{SO}_{4}$ solution $\left(0.5 \mathrm{~mol} \mathrm{~L}^{-1}\right)$.

5 Subsequently, CO was removed from the electrolyte by purging with $\mathrm{N}_{2}$ for 25 minutes, and

6 three consecutive cyclic voltammetries were run with a scan rate of $10 \mathrm{mV} \mathrm{s}^{-1}$ within the

7 potential range of 0.01 to $1.01 \mathrm{~V}$ versus RHE reference electrode. The electrochemical surface

8 areas $(E S A)^{21}$ for $\mathrm{CO}$ stripping were obtained by integrating the area under each $\mathrm{CO}$ oxidation

9 peaks in the first voltammetric cycle $\left(\mathrm{Q}_{\mathrm{co}}\right.$, in $\left.\mathrm{mC}\right)$, these were then divided by the charge

10 needed to oxidize a CO monolayer adsorbed onto a Pt surface $\left(Q_{c o}=420 \mu \mathrm{C} \mathrm{cm}^{-2}\right)$. These

11 values were then normalized by the mass of Pt on each electrode and the ECSA was obtained 12 in $\mathrm{m}^{2} \mathrm{~g}^{-1}$.

For the oxygen reduction reaction (ORR), linear scanning voltammograms were

14 collected with a scan rate of $0.01 \mathrm{~V} \mathrm{~s}^{-1}$ in an ultrapure $\mathrm{O}_{2}$ saturated $\mathrm{H}_{2} \mathrm{SO}_{4}$ electrolyte $(0.5 \mathrm{~mol}$

$15 \mathrm{~L}^{-1}, 30$ minutes of $\mathrm{O}_{2}$ purge) in the potential range between 1.21 and $0.21 \mathrm{~V}$ ( $v s \mathrm{RHE}$ ) in 16 different rotation speeds ( $\omega$ ) from 100 to $2500 \mathrm{rpm}$. For experiments performed under light

17 irradiation, a UV LED stick (UVP Pen-Ray (R) Light source) was used. All the analyses were 18 performed in triplicate. 
In order to study the stability of the electrocatalysts, the most promising catalyst

$2\left(\mathrm{Pt} / \mathrm{TiO}_{2}-2 / \mathrm{C}\right)$ was compared to the commercial material (Pt/C E-TEK) in accelerated stress

3 tests. A typical test was performed in $\mathrm{H}_{2} \mathrm{SO}_{4}\left(0.5 \mathrm{~mol} \mathrm{~L}^{-1}\right)$ as support electrolyte. An ORR

4 polarization curve was then collected with a scan rate of $0.01 \mathrm{~V} \mathrm{~s}^{-1}$ in an ultrapure $\mathrm{O}_{2}$ saturated

$5 \quad \mathrm{H}_{2} \mathrm{SO}_{4}$ electrolyte $\left(0.5 \mathrm{~mol} \mathrm{~L}^{-1}, 30\right.$ minutes of $\mathrm{O}_{2}$ purge $)$ in the potential range between 1.21

6 and $0.21 \mathrm{~V}$ ( $v s \mathrm{RHE}$ ) in different rotation speeds ( $\omega$ ) from 100 to $2500 \mathrm{rpm}$. After performing

7 the ORR, the electrolyte was switched for a fresh one and $\mathrm{N}_{2}$ was bubbled for 30 minutes

8 before performing the cycles, 1000 cyclic voltammetries were run with a scan rate of $100 \mathrm{mV}$

$9 \mathrm{~s}^{-1}$ within the potential range of 0.01 to $1.01 \mathrm{~V}$ versus RHE. Oxygen was once again bubbled

10 for 30 minutes and ORR was performed in the same conditions as previously established.

Results and discussion

Figure S1A and B show SEM and HRTEM images of the $\mathrm{TiO}_{2}$ colloidal spheres that were employed supports for the $\mathrm{Pt} / \mathrm{TiO}_{2}$ materials. $\mathrm{The}^{\mathrm{TiO}}{ }_{2}$ spheres displayed spherical shape and were $267.8 \pm 37.8 \mathrm{~nm}$ in diameter. Although they appear to be smooth from SEM images,

17 HRTEM results revealed that they are comprised of $\mathrm{TiO}_{2}$ nanocrystallites (around $10 \mathrm{~nm}$ in 18 size). They were crystallized as anatase according to previously reported XRD and Raman 19 data. $^{19,22}$ The $\mathrm{TiO}_{2}$ colloidal spheres were employed as seeds for Pt deposition at their surface

21 with controllable sizes and coverage by a facile route based on sequential deposition steps as 
1 depicted in Figure S2. This approach employed $\mathrm{PtCl}_{6}{ }^{2-}$ as the Pt precursor, ascorbic acid as a

2 reducing agent, $\mathrm{PVP}$ as a stabilizer, water as the solvent, and $90^{\circ} \mathrm{C}$ as the reaction temperature.

3 The loading and coverage of Pt at the surface could be controlled by performing successive

4 deposition steps, which allows for the understanding of how these parameters affect the

5 electrocatalytic activity of the generated materials towards the ORR. Specifically, three Pt

6 deposition steps were performed, which led to $\mathrm{Pt} / \mathrm{TiO}_{2}-1, \mathrm{Pt} / \mathrm{TiO}_{2}-2$, and $\mathrm{Pt} / \mathrm{TiO}_{2}-3$ materials

7 (obtained after one, two, and three Pt deposition steps, respectively).

SEM images for the $\mathrm{Pt} / \mathrm{TiO}_{2}-1, \mathrm{Pt} / \mathrm{TiO}_{2}-2$, and $\mathrm{Pt} / \mathrm{TiO}_{2}-3$ materials (Figure $1 \mathrm{~A}-\mathrm{C}$,

9 respectively) indicate the efficient deposition of $\mathrm{Pt} N \mathrm{NS}$ at the $\mathrm{TiO}_{2}$ supports displaying a

10 uniform surface dispersion, spherical shape, and uniform sizes. The Pt content and coverage

11 at the $\mathrm{TiO}_{2}$ surface could be tailored by performing sequential reduction steps. The ICP-OES

12 analyses indicated the presence of $20.1,31.0$, and $38.4 \mathrm{wt} . \%$ of $\mathrm{Pt}$ in the $\mathrm{Pt} / \mathrm{TiO}_{2}-1, \mathrm{Pt} / \mathrm{TiO}_{2}-2$,

13 and $\mathrm{Pt} / \mathrm{TiO}_{2}-3$ samples, respectively. Moreover, Pt NPs diameters calculated from the SEM

14 images corresponded to $11.9 \pm 3.0,16.0 \pm 2.2$, and $20.1 \pm 2.1 \mathrm{~nm}$ (histograms on Figure S3),

15 respectively. HRTEM images for the $\mathrm{Pt} / \mathrm{TiO}_{2}-1, \mathrm{Pt} / \mathrm{TiO}_{2}-2$, and $\mathrm{Pt} / \mathrm{TiO}_{2}-3$ samples (Figure 1D-F,

16 respectively) revealed that the individual Pt NPs were comprised of aggregates made up of

17 individual, smaller Pt NPs measuring about $3 \mathrm{~nm}$ in size (estimated based on TEM images).

18 While a lower Pt coverage at the $\mathrm{TiO}_{2}$ surface can be observed for both $\mathrm{Pt} / \mathrm{TiO}_{2}-1$ and $\mathrm{Pt} / \mathrm{TiO}_{2}$ -

192 samples (Figure 1D and $\mathbf{E}$ ), the highest coverage was detected in the $\mathrm{Pt} / \mathrm{TiO}_{2}-3$ material

20 (Figure 1F). 
After the syntheses, the $\mathrm{Pt} / \mathrm{TiO}_{2}-1, \mathrm{Pt} / \mathrm{TiO}_{2}-2$, and $\mathrm{Pt} / \mathrm{TiO}_{2}-3$ samples were

2 incorporated onto Vulcan XC-72 Carbon $\left(\mathrm{Cabot}^{\circledR}\right)$ by wet impregnation. This led to $\mathrm{Pt} / \mathrm{TiO}_{2}-$

$31 / \mathrm{C}, \mathrm{Pt} / \mathrm{TiO}_{2}-2 / \mathrm{C}$, and $\mathrm{Pt} / \mathrm{TiO}_{2}-3 / \mathrm{C}$ materials, respectively. In all cases, the $\mathrm{Pt} / \mathrm{TiO}_{2}$ loading

4 corresponded to $10 \mathrm{wt} . \%$, reaching the overall Pt loading of $2.01,3.10$, and $3.84 \mathrm{wt} . \%$ for

$5 \mathrm{Pt} / \mathrm{TiO}_{2}-1 / \mathrm{C}, \mathrm{Pt} / \mathrm{TiO}_{2}-2 / \mathrm{C}$, and $\mathrm{Pt} / \mathrm{TiO}_{2}-3 / \mathrm{C}$, respectively. Figure $\mathrm{S} 4$ shows the $\mathrm{XRD}$ profiles for

6 the $\mathrm{Pt} / \mathrm{TiO}_{2}-1 / \mathrm{C}, \mathrm{Pt} / \mathrm{TiO}_{2}-2 / \mathrm{C}$, and $\mathrm{Pt} / \mathrm{TiO}_{2}-3 / \mathrm{C}$ materials. The diffractograms show the

7 characteristic reflections assigned to $\mathrm{TiO}_{2}$ anatase, $f c c \mathrm{Pt}$, and carbon. This indicates that our

8 wet impregnation approach was effective for the incorporation of $\mathrm{Pt} / \mathrm{TiO}_{2}$ onto the carbon

9 support.

In order to probe the generation of ORR reactive sites in the $\mathrm{Pt} / \mathrm{TiO}_{2}-3 / \mathrm{C}$ materials as

11 a result of metal-support interactions, the samples were studied by XPS. Figure 2A-D shows

12 the Ti 2p, Pt 4f, C 1s, and O 1s core level XPS spectra along with their fitting and deconvoluted

13 curves, obtained for the $\mathrm{Pt} / \mathrm{TiO}_{2}-1 / \mathrm{C}, \mathrm{Pt} / \mathrm{TiO}_{2}-2 / \mathrm{C}$, and $\mathrm{Pt} / \mathrm{TiO}_{2}-3 / \mathrm{C}$ materials. Data for Vulcan

14 XC-72 carbon is also shown for comparison. The corresponding XPS parameters obtained from

15 the spectra are shown in Table $\mathbf{1}$ (for Ti, Pt, and $\mathrm{O}$ ) and $\mathbf{2}$ (for $\mathrm{C}$ ). The Ti $2 \mathrm{p}$ spectrum (Figure

16 2A) displayed doublet peaks at $459.4 \mathrm{eV}$ and $465.1 \mathrm{eV}$ assigned to Ti $2 p_{3 / 2}$ and Ti $2 p_{1 / 2}$,

17 respectively. The splitting width between the two peaks was $5.7 \mathrm{eV}$, indicating the presence

18 of only the $\mathrm{Ti}^{4+}$ chemical state. ${ }^{23} \mathrm{Ti} 2 \mathrm{p}$ peaks were slightly shifted towards higher binding

19 energies as compared to those in $\mathrm{TiO}_{2}$, which indicates a change in the $\mathrm{Ti}$ chemical

20 environment possibly due to strong interactions with the Carbon support (such as the

21 formation of Ti-O-C bonds). ${ }^{24}$ 

components had an asymmetric shape which is typical for $\mathrm{Pt}^{0.25,26}$ The peaks located at 71.5 and 74.9 eV can be assigned to $\mathrm{Pt} 4 \mathrm{f}_{7 / 2}$ and $\mathrm{Pt} 4 \mathrm{f}_{5 / 2}$ of $\mathrm{Pt}^{0}$, respectively. The slight shift towards higher binding energy values compared to literature values $(71.0 \mathrm{eV})$ is attributed to metalsupport interaction and to small Pt NPs sizes. ${ }^{26,27}$ This positive shift may also suggest metasupport interactions between $\mathrm{TiO}_{2}$ and $\mathrm{Pt}$. This interaction can modify the electronic properties of Pt by increasing the Pt d-vacancy via electronic donation to Lewis acid centers

8 such as $\mathrm{Ti}^{\mathrm{x}+}$ at the $\mathrm{Pt} / \mathrm{TiO}_{2}$ interface. ${ }^{28-30}$ peaks (Figure 2C). The lowest binding energy and dominant peak at about $284.5 \mathrm{eV}$ corresponds to the graphitic carbon phase, ${ }^{31}$ while the peak at around $286.0 \mathrm{eV}$ is assigned to hydrocarbons $(\mathrm{C}-\mathrm{H})$ from defects on the graphitic structure. ${ }^{32}$ Three carbon-oxygen bonding structures for the $-\mathrm{C}-\mathrm{OH},>\mathrm{C}=\mathrm{O}$ and $-\mathrm{COOH}$ can also be observed at approximately 287.5 , 289.2 and $290.8 \mathrm{eV}$, respectively. The subpeak located at higher than $292.8 \mathrm{eV}$ is related to $\pi$ $\rightarrow \pi *$ plasmonic excitation. ${ }^{33}$ It is noteworthy that it has been established that acidic oxygenated species contribute to the generation of $\mathrm{H}_{2} \mathrm{O}_{2}$ in the ORR. ${ }^{34,35}$ In our case, XPS data

17 indicate that the $\mathrm{Pt} / \mathrm{TiO}_{2}-2 / \mathrm{C}$ sample presented the lowest amount of oxygenated species on

18 the surface (as seen on $I_{\text {oxy }} / I_{c}$ depicted in Table 2). Therefore, it can be anticipated that this

19 material would generate the lowest amount of $\mathrm{H}_{2} \mathrm{O}_{2}$ during the reaction and lead to a higher

20 ORR current density relative to the other samples $\left(\mathrm{Pt} / \mathrm{TiO}_{2}-1 / \mathrm{C}\right.$ and $\left.\mathrm{Pt} / \mathrm{TiO}_{2}-3 / \mathrm{C}\right){ }^{22}$ 
2 1s peaks could be deconvoluted in three peaks. The first component $\left(\mathrm{O}_{1}\right)$ centered at $531 \mathrm{eV}$

3 was attributed to the lattice oxygen in the oxides and $\mathrm{C}=\mathrm{O}$ functional groups. The second and

4 dominant component $\left(\mathrm{O}_{\Perp}\right)$ located at $533 \mathrm{eV}$ was attributed to chemisorbed oxygen species

5 (such as $\mathrm{OH}^{-}$) and functional $\mathrm{C}-\mathrm{O}$ groups. The last component $\left(\mathrm{O}_{\text {III }}\right)$ with $\mathrm{BE}$ around $536 \mathrm{eV}$

6 were characteristic of adsorbed water. ${ }^{24,36}$

After probing the metal-support interactions and generation of reactive surface species by XPS, we investigated their electroactive areas by CO stripping as described in Figure

9 S5. The $\mathrm{Pt} / \mathrm{TiO}_{2} / \mathrm{C}$ materials presented lower onset potential for carbon monoxide oxidation when compared to commercial Pt/C E-TEK, a behavior related to the interaction between Pt

11 and $\mathrm{TiO}_{2}$. This interaction (as suggested by XPS data) decreases the adsorption of $\mathrm{CO}$ at the metal surface facilitating the oxidation. ${ }^{37} \mathrm{~A}$ main current density peak was detected between

130.76 and $0.80 \mathrm{~V}$ vs RHE (Reversible Hydrogen Electrode) for all materials, which is assigned to 14 the $\mathrm{CO}$ oxidation on the Pt sites interacting with $\mathrm{sp}^{3}$ disordered carbon. ${ }^{1,38}$ In addition, a 15 shoulder at lower potentials was observed ( $0.46 \mathrm{~V}$ vs $\mathrm{RHE}$ ) for the $\mathrm{Pt} / \mathrm{TiO}_{2}-3 / \mathrm{C}$, which can be 16 assigned to the partial agglomeration of Pt NPs on the $\mathrm{TiO}_{2}$ surface caused by the higher Pt 17 coverage in this material. ${ }^{39}$ The ESA (electrochemical surface area) and ECSA (electrochemical 18 active surface area) of the materials calculated from the CO-stripping experiments are 19 depicted in Table $\mathbf{S 1} .{ }^{40}$ It can be observed that the ECSA increased with the Pt loadings, 20 corresponding to $2.41,9.78$, and $25.2 \mathrm{~m}^{2} \mathrm{~g}^{-1}$ for $\mathrm{Pt} / \mathrm{TiO}_{2}-1 / \mathrm{C}, \mathrm{Pt} / \mathrm{TiO}_{2}-2 / \mathrm{C}$, and $\mathrm{Pt} / \mathrm{TiO}_{2}-3 / \mathrm{C}$ 21 materials, respectively. Here, the Pt content in the samples increases in the order of $\mathrm{Pt} / \mathrm{TiO}_{2^{-}}$ 
$13 / \mathrm{C}>\mathrm{Pt} / \mathrm{TiO}_{2}-2 / \mathrm{C}>\mathrm{Pt} / \mathrm{TiO}_{2}-1 / \mathrm{C}$ (samples 1,2 , and 3 were prepared after successive $\mathrm{Pt}$

2 deposition steps). Therefore, the Pt ECSA increases with the Pt loading in the Pt/TiO2/C

3 samples. However, it is important to note that these ECSA values were significantly lower

4 as compared to Pt/C E-TEK $\left(68.2 \mathrm{~m}^{2} \mathrm{~g}^{-1}\right)$. This is probably due to the aggregation of the Pt NPs

5 on the $\mathrm{TiO}_{2}$ surface as observed by HRTEM.

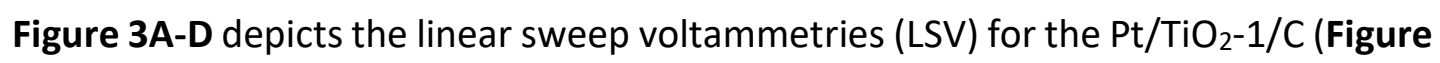

7 3A), $\mathrm{Pt} / \mathrm{TiO}_{2}-2 / \mathrm{C}$ (Figure 3B), and $\mathrm{Pt} / \mathrm{TiO}_{2}-3 / \mathrm{C}$ (Figure 3C) and $\mathrm{Pt} / \mathrm{C}$ E-TEK (Figure 3D) materials

8 towards the ORR performed in $\mathrm{O}_{2}$ saturated $\mathrm{H}_{2} \mathrm{SO}_{4}\left(0.5 \mathrm{~mol} \mathrm{~L}^{-1}\right)$ at different rotation rates

9 (from $100 \mathrm{rpm}$ to $2500 \mathrm{rpm}$ as indicated by the colors in the inset, Figure 3A). The detected

10 currents were normalized by the geometric surface areas of the electrodes $\left(0.196 \mathrm{~cm}^{2}\right.$ for the

11 disk and $0.037 \mathrm{~cm}^{2}$ for the ring) and presented as current densities. Figure $\mathbf{3 E}-\mathbf{H}$ depicts the

12 disk currents for the ORR, respectively, using each electrocatalyst shown in Figure 3A-D.

13 These results show an increase in ring current density values (Figure 3A-D) on potentials lower

14 than $0.80 \mathrm{~V}$ vs RHE, which indicates the conversion of $\mathrm{O}_{2}$ onto $\mathrm{H}_{2} \mathrm{O}_{2}$ as detected by its

15 oxidation on the ring electrode. ${ }^{41-44}$ However, the disk current density (Figure $\mathbf{3 E}-\mathbf{H}$ ) is

16 lowered in potentials below $0.80 \mathrm{~V}$, which indicates the formation of $\mathrm{H}_{2} \mathrm{O}$.

Additionally, LSV of the ORR on the disk indicates a mixed kinetic-diffusion control

18 region between potentials of $0.90 \mathrm{~V}$ and $0.60 \mathrm{~V}$. This region is narrower under low rotations

19 and becomes larger at higher rotations. The region between $0.60 \mathrm{~V}$ and lower potentials is

20 assigned to the diffusional control region. This behavior is normally seen for Pt-based 
1 electrocatalysts. ${ }^{45}$ The disk's limiting current density increased gradually with the rotation

2 rate, as expected for a diffusional-controlled reaction. ${ }^{46}$ and 2: ${ }^{47}$

$$
\begin{aligned}
& p\left(H_{2} O\right)=2 \times \frac{\frac{i_{r}}{N_{C}}}{i_{d}+\frac{i_{r}}{N_{c}}} \\
& n=4 \times \frac{i_{d}}{i_{d}+\frac{i_{r}}{N_{c}}}
\end{aligned}
$$

where $\mathrm{N}_{c}$ is the collection factor (experimentally determined as $\mathrm{N}_{c}=0.37$ ), $\mathrm{i}_{d}$ is the disk current,

$9 \quad \mathrm{i}_{r}$ is the ring current. These values are listed in Table 3. A small amount of electrogenerated hydrogen peroxide is observed from the ring current densities presented in Figure 3. When comparing the limiting current densities of the ring and disk on the commercial material, we can see that the ring current density is about 2500 times lower than the disk, confirming that these electrodes produce mainly water (low hydrogen peroxide current). Hence, the number of electrons is closer to 4. the experimental values obtained for Pt/C E-TEK were close to the theoretical ones (3.98 electrons $98.8 \%$ water), the number of electron and water percentages were compared in the diffusional region for all materials. These values become lower when the $\mathrm{Pt}$ loading on $\mathrm{TiO}_{2}$ increases, which could be assigned to the preferential 4-electron mechanism of Pt for the ORR. 
1 suggested that the ORR on the disk, and consequently the oxidation of $\mathrm{H}_{2} \mathrm{O}_{2}$ on the ring, occur

2 as a function of the applied potential. Our results suggest that there are probably two

3 mechanisms of formation of hydrogen peroxide, one at lower overpotentials and one at

4 higher overpotentials. In order to better understand the reaction mechanism, Tafel curves

5 were plotted from RDE data by the mass-transport correction of the current density measured

6 for rotating disk electrodes and are presented in Figure 4 according to Equation 3:

7

$8 \quad j_{k}=\frac{j_{d^{* j}}}{j_{d^{-j}}}$

10 where $\mathrm{j}$ is the experimentally measured current density, $\mathrm{j}_{\mathrm{d}}$ is the obtained diffusion-limited

11 current density, and $\mathrm{j}_{\mathrm{k}}$ is the kinetic current density without the mass-transport effect. These

12 values were calculated using the current density normalized by geometric area. The Tafel

13 curves for the electrocatalysts presented two different regions, a behavior which is expected

14 for Pt-based catalysts. At lower overpotentials, all the electrocatalysts presented slopes

15 between -70 and $-90 \mathrm{mV} \mathrm{dec}{ }^{-1}$, reaching the highest value on $\mathrm{Pt} / \mathrm{TiO}_{2}-1 / \mathrm{C}\left(86.5 \mathrm{mV} \mathrm{dec}^{-1}\right)$,

16 which indicates that the mechanism of oxygen adsorption is similar to bulk Pt at $1.06-0.96 \mathrm{~V}$

17 (vs RHE) potentials. ${ }^{14,18,48}$ However, at higher overpotentials, there is an increase on the slope

18 with the decrease in module of the Pt amount on the electrocatalyst from $-124.7 \mathrm{mV} \mathrm{dec}^{-1}$

19 (Pt/C E-TEK) to $-135.2 \mathrm{mV} \mathrm{dec}^{-1}\left(\mathrm{Pt} / \mathrm{TiO}_{2}-1 / \mathrm{C}\right) .{ }^{49}$ This observation indicates that the current

20 densities are related to the oxygen adsorption energy on the electrocatalyst surface and that

21 the first electron transfer is the determining step of the ORR. ${ }^{16}$ These slope values were also 
1 observed for other $\mathrm{TiO}_{2}$-based electrocatalysts. ${ }^{14,16,49}$ When comparing the Tafel plot for all

2 the materials employed in this work, we can notice that the $\mathrm{Pt} / \mathrm{TiO}_{2}-2 / \mathrm{C}$ material presented a

3 profile very similar to the Pt/C E-TEK material, even though it presents lower Pt content. Previous studies have shown that high slopes on the Tafel plot are normally associated with the rate determining step of the $\mathrm{ORR}$, the $\mathrm{O}_{2}$ adsorption onto the metal. ${ }^{50}$

6 Tafel slopes normally increase on materials with lower Pt contents, which indicates that the

7 mechanism tends to involve a 2-electron reaction. This was also observed for our materials

8 when compared to the commercial Pt/C. ${ }^{51}$ According to Shinagawa et al. ${ }^{50}$, the mechanism of

9 the ORR is based on three different surface covering species, which are responsible for the

10 slopes on the Tafel plot. At lower overpotentials, the theoretical slopes can vary from 40 to

$11120 \mathrm{mV} \mathrm{dec}^{-1}$ depending on the adsorbed species contributing to the rate determining step.

12 As the slope lowers, it indicates there are more $\mathrm{MOO}^{-}$and $\mathrm{MOOH}$ species contributing to the

13 rate-determining step of the reaction, while at higher slopes the rate determining step is

14 governed by MOO adsorption. Hence, while the reaction on the Pt/C E-TEK catalyst is

15 determined initially by MOO groups, the reaction also depended on the generation of $\mathrm{MOO}^{-}$

16 and $\mathrm{MOOH}$ groups in the $\mathrm{Pt} / \mathrm{TiO}_{2} / \mathrm{C}$ materials. On the other hand, at higher overpotentials,

17 the Tafel slope is normally $\geq 120 \mathrm{mV} \mathrm{dec}^{-1}$, which indicates that the MOO and MOOH species

18 are converting into $\mathrm{MOO}^{-}$species. Thus, the detected higher slopes show that the conversion

19 starts in lower overpotentials and/or these catalysts already present a high number of $\mathrm{MOO}^{-}$

20 species on their surface. This figure also shows that while the change in slope occurred at

$210.775 \mathrm{~V}$ for the Pt/C E-TEK material, this change was only seen at higher overpotentials for 
1 the $\mathrm{Pt} / \mathrm{TiO}_{2} / \mathrm{C}$ materials. Moreover, based on DFT simulations, ${ }^{52}$ a strong interaction between

$2 \mathrm{Pt}$ and $\mathrm{TiO}_{2}$ is presumed due to the overlapping of the $\mathrm{TiO}_{2}$ bonding orbitals with the Pt d-

3 orbital. These calculations also indicate a strong interaction between $\mathrm{Ti}$ and $\mathrm{Pt}$ that could

4 result in a negative overall net charge in this structure which could strengthen the Pt- $\mathrm{O}_{\text {ads }}$

5 bond. Therefore, the desorption process could become slow in the high overpotential region,

6 thus increasing the Tafel plot as observed in our data.

7 In order to better compare the relative ORR electrocatalytic activity of our materials, the

8 ORR linear scanning voltammetries at $1600 \mathrm{rpm}$ rotation rate were plotted as shown in Figure

9 5A. In addition, the electrocatalytic activity normalized by geometric mass (left-hand side)

10 and Pt mass on the electrode (right-hand side) at $0.80 \mathrm{~V}$ (vs RHE) are shown in Figure 5B. The

11 Pt/C E-TEK material presented a more positive onset potential for the ORR (0.89 V) followed

12 by $\mathrm{Pt} / \mathrm{TiO}_{2}-2 / \mathrm{C}(0.88 \mathrm{~V}), \mathrm{Pt} / \mathrm{TiO}_{2}-3 / \mathrm{C}(0.84 \mathrm{~V})$, and $\mathrm{Pt} / \mathrm{TiO}_{2}-1 / \mathrm{C}(0.82 \mathrm{~V})$. Here, it is important to

13 note that the $\mathrm{Pt} / \mathrm{TiO}_{2} / \mathrm{C}$ materials have less than half $\mathrm{Pt}$ content in their composition

14 compared to the commercial electrocatalyst. In agreement with the ORR onset potential, the

15 number of transferred electrons follows the trend: $\mathrm{Pt} / \mathrm{C} \mathrm{E}-\mathrm{TEK}>\mathrm{Pt} / \mathrm{TiO}_{2}-2 / \mathrm{C}>\mathrm{Pt} / \mathrm{TiO}_{2}-3 / \mathrm{C}>$

$16 \mathrm{Pt} / \mathrm{TiO}_{2}-1 / \mathrm{C}$, indicating that the reaction is kinetically favorable in this order. Interestingly, even though the electrodes covered by $\mathrm{Pt} / \mathrm{TiO}_{2} / \mathrm{C}$ hybrids have $\mathrm{Pt}$

18 loadings that range from threefold to fivefold lower than the one containing Pt/C E-TEK, they

19 still present similar limiting diffusional current densities. ${ }^{53}$ This led to much higher activities

20 when the data is normalized by $\mathrm{Pt}$ mass in Figure 5B. Specifically, the $\mathrm{Pt} / \mathrm{TiO}_{2}-2 / \mathrm{C}$ material

21 displayed a starting reduction potential close to Pt/C E-TEK $(0.89 \mathrm{~V}$ and $0.88 \mathrm{~V}$ vs RHE, 
1 respectively). The higher activity of the $\mathrm{Pt} / \mathrm{TiO}_{2}-2 / \mathrm{C}$ material could be attributed to its lowest

2 number of acidic oxygenated species at the surface as determined by XPS. These sites

3 decrease the $\mathrm{H}_{2} \mathrm{O}_{2}$ formation thus enhancing the water production and the current on the

4 disk relative to the other materials ${ }^{22}$. This material also displays less Pt NPs aggregation at the

5 surface as compared to $\mathrm{Pt} / \mathrm{TiO}_{2}-3 / \mathrm{C}$ (Figure 1 ). It is noteworthy that the $\mathrm{Pt} / \mathrm{TiO}_{2}-1 / \mathrm{C}$ sample

6 presented the highest $\mathrm{H}_{2} \mathrm{O}_{2}$ production, which can also be attributed to the higher exposure

7 of anatase $\mathrm{TiO}_{2}$ at the surface as a result of lower Pt coverage. ${ }^{22,54}$

Our data indicate that the control over the Pt NPs coverage at the $\mathrm{TiO}_{2}$ surface

9 significantly influences their electrocatalytic activities towards the ORR. In this case, rather

10 than an increase in activity with the Pt loading, a volcano-type relationship was observed, in

11 which the sample produced by two Pt deposition steps $\left(\mathrm{Pt}_{\mathrm{TiO}}-\mathrm{T}-\mathrm{C}\right)$ displayed the highest

12 activities due to the equilibrium between optimum Pt loading/surface coverage and the

13 presence of surface reactive sites as enabled by metal-support interactions.

14 We also evaluated the stability of the $\mathrm{Pt} / \mathrm{TiO}_{2}-2 / \mathrm{C}$ material relative to $\mathrm{Pt} / \mathrm{C}$ E-TEK by

15 performing accelerated stress tests (AST) as shown in Figure 6. The initial and final ORR

16 polarization curves are depicted as solid and dashed traces, respectively, in Figure 6A. The

17 AST curves for the Pt/C E-TEK and $\mathrm{Pt} / \mathrm{TiO}_{2}-2 / \mathrm{C}$ are shown in black and red, respectively. It can

18 be observed that a decrease in activity was detected for both materials after the tests.

19 However, when comparing their half-wave potential before and after the AST, $E_{1 / 2}$, (Figure

20 6B), a more significant decrease is detected for Pt/C E-TEK, from 0.747 to $0.646 \mathrm{~V} v s \mathrm{RHE}$

21 compared to $\mathrm{Pt} / \mathrm{TiO}_{2}-2 / \mathrm{C}$, which corresponded from 0.727 to $0.697 \mathrm{~V}$ vs RHE. When 
1 comparing half-wave potentials, shifts to smaller regions indicate an activity loss, thus, since

2 for the commercial materials the shift is higher (approximately $0.31 \mathrm{~V} v s \mathrm{RHE}$ ) when compared

3 to $\mathrm{Pt} / \mathrm{TiO}_{2}-2 / \mathrm{C}$ (approximately $0.24 \mathrm{~V}$ vs $\mathrm{RHE}$ ). Moreover, after the AST, the number of

4 electrons involved in the reactions and water percentages lowered for both materials, as seen

5 in Table S2. While the mean electron number was of 3.94 and 3.92 on the $\mathrm{Pt} / \mathrm{TiO}_{2}-2 / \mathrm{C}$ and

6 Pt/C E-TEK, they produced 97.1 and $96.1 \%$ of water, respectively. This further shows the low

7 loss of overall activity of $\mathrm{Pt} / \mathrm{TiO}_{2}-2 / \mathrm{C}$ compared to the Pt/C E-TEK.

In addition to metal-support interactions, the utilization of $\mathrm{TiO}_{2}$ as support also

9 enables the harvesting of its photocatalytic properties to further improve activities. Therefore,

10 the influence of UV irradiation on the electrocatalytic activity of the $\mathrm{Pt} / \mathrm{TiO}_{2}-2 / \mathrm{C}$

11 electrocatalyst was also evaluated. The effect of light irradiation was probed in

12 chronoamperometry experiments performed at $0.51 \mathrm{~V}$ ( $v s \mathrm{RHE}$ ) as shown in Figure S6A and

13 the activity towards the ORR by linear scanning voltammogram as shown in Figure S6B

14 (rotation rate of $1600 \mathrm{rpm}$ in $\mathrm{O}_{2}$ saturated $0.5 \mathrm{~mol} \mathrm{~L}^{-1} \mathrm{H}_{2} \mathrm{SO}_{4}$ solution). Here, the activity under

15 UV excitation was compared with its activity in the absence of UV excitation. Figure S6A

16 shows a chronoamperometric assay while applying to the electrode UV light pulses of about

17150 seconds. It was observed that under UV light excitation the current density increased in

18 about $4 \mathrm{~mA} \mathrm{~cm}^{-2}$ due to the light excitation. The voltammograms on Figure S6B revealed a

19 slight shift to more positive potentials $(\sim 30 \mathrm{mV})$ and an increase of $11.3 \%$ on the limiting

20 diffusion current density under UV-excitation. This indicates that the utilization that $\mathrm{TiO}_{2}$

21 based electrocatalysts and UV light excitation can be employed to further improve the 
1 electrocatalytic activities towards the ORR. It is anticipated that further optimizations can lead

2 to further improvements both in the photoelectrocatalytic activities and in the use of visible

3 light (instead of UV) by $\mathrm{TiO}_{2}$ doping or use Au NPs (harvesting of plasmonic effects).

4

\section{Conclusions}

We investigated herein how Pt surface coverage in hybrid materials comprised of Pt

8 NPs supported on $\mathrm{TiO}_{2}$ colloidal spheres $\left(\mathrm{Pt} / \mathrm{TiO}_{2}\right)$ influence their electrocatalytic activities

9 towards the ORR. It was demonstrated that, by employing $\mathrm{TiO}_{2}$ colloidal spheres as physical

10 templates, the uniform deposition of monodisperse and spherical Pt NPs $\sim 3 \mathrm{~nm}$ could be

11 achieved. The Pt coverage could be tuned as a function of the deposition steps. After

12 incorporating the $\mathrm{Pt} / \mathrm{TiO}_{2}$ materials into Vulcan $\mathrm{XC} 72$ Carbon (to produce $\mathrm{Pt} / \mathrm{TiO}_{2} / \mathrm{C}$ materials),

13 the electrocatalytic activities towards the ORR as well as the reaction and enhancement

14 mechanisms were investigated. Our results demonstrated that the control over the Pt

15 coverage at the surface plays a pivotal role over the optimization of activities, in which a

16 relationship among Pt content at the $\mathrm{TiO}_{2}$ surface, the generation of surface reactive sites as

17 a result of metal-support interactions, and ORR performance were unraveled. More

18 specifically, the material produced from two Pt deposition steps displayed the highest activity,

19 which was also superior as compared to commercial Pt/C E-TEK even at lower Pt loadings

20 (between 2.0 and $4.0 \mathrm{wt} . \%$ of Pt on the final material). The variations in catalytic activity could

21 be explained by the presence and concentration of surface reactive groups, such as adsorbed 
1 oxygenated species as a function of the Pt coverage. Moreover, the presence of $\mathrm{TiO}_{2}$ as

2 support enabled increased stability relative to PT/C ETEK. We believe that improvements on

3 the $\mathrm{Pt} / \mathrm{TiO}_{2} / \mathrm{C}$ interface may allow for the reduction on the voltage loss relative to $\mathrm{Pt} / \mathrm{C}$

4 systems and thus further optimizations in performance. These results illustrate that the

5 understanding of the electrocatalytic enhancement mechanism together with the controlled

6 synthesis of Pt-based nanomaterials can lead to tailored surface properties and

7 electrocatalytic activities.

9 Supporting Information. SEM and HRTEM images, schematics of the synthesis, histograms of

10 size distribution, DRX patterns, CO-stripping and CVs, photoelectrocatalytic experiments, ESA

11 and ESCA values, and RRDE data obtained after the AST tests.

\section{Acknowledgments}

14 This work was supported by FAPESP (grant numbers 2015/21366-9, 2015/26308-7, 15 2017/21846-6) and the Serrapilheira Institute (Grant Serra-1709-16900). This study was 16 financed in part by the Coordenação de Aperfeiçoamento de Pessoal de Nível Superior - Brazil

17 (CAPES) - Finance Code 001. P.H.C.C and M.C.S. thank the CNPq for the research fellowships.

18 E.C.M.B. and L. S. P. thanks FAPESP for the fellowship (grant numbers 2015/11452-5 and 19 2016/00819-8, respectively). We also thank the Brazilian Synchrotron Light Laboratory (LNLS, 20 CNPEM) for XPS analysis. 
3 (1) Estudillo-Wong, L. A.; Luo, Y.; Díaz-Real, J. A.; Alonso-Vante, N. Enhanced Oxygen

\section{References} Reduction Reaction Stability on Platinum Nanoparticles Photo-Deposited onto OxideCarbon Composites. Appl. Catal. B Environ. 2016, 187, 291-300.

(1) https://doi.org/10.1016/j.apcatb.2016.01.030.

(2) ten Elshof, J. E.; Yuan, H.; Gonzalez Rodriguez, P. Two-Dimensional Metal Oxide and Metal Hydroxide Nanosheets: Synthesis, Controlled Assembly and Applications in Energy Conversion and Storage. Adv. Energy Mater. 2016, 6 (23), 1600355. https://doi.org/10.1002/aenm.201600355.

(3) Mistry, H.; Varela, A. S.; Kühl, S.; Strasser, P.; Cuenya, B. R. Nanostructured Electrocatalysts with Tunable Activity and Selectivity. Nat. Rev. Mater. 2016, 16009. https://doi.org/10.1038/natrevmats.2016.9.

(4) Kleijn, S. E. F.; Lai, S. C. S.; Koper, M. T. M.; Unwin, P. R. Electrochemistry of Nanoparticles. Angew. Chem. Int. Ed. 2014, 53 (14), 3558-3586. https://doi.org/10.1002/anie.201306828.

(5) Cheng, X.; Li, Y.; Zheng, L.; Yan, Y.; Zhang, Y.; Chen, G.; Sun, S.; Zhang, J. Highly Active, Stable Oxidized Platinum Clusters as Electrocatalysts for the Hydrogen Evolution Reaction. Energy Environ. Sci. 2017, 10 (11), 2450-2458. https://doi.org/10.1039/C7EE02537H.

(6) Shao, M.; Chang, Q.; Dodelet, J.-P.; Chenitz, R. Recent Advances in Electrocatalysts for 
Oxygen Reduction Reaction. Chem. Rev. 2016, 116 (6), 3594-3657. https://doi.org/10.1021/acs.chemrev.5b00462.

(7) Li, Y.; Hart, J. L.; Taheri, M. L.; Snyder, J. D. Morphological Instability in Topologically Complex, Three-Dimensional Electrocatalytic Nanostructures. ACS Catal. 2017, 7 (11), 7995-8005. https://doi.org/10.1021/acscatal.7b02398.

(8) Huang, Z. F.; Wang, J.; Peng, Y.; Jung, C. Y.; Fisher, A.; Wang, X. Design of Efficient Bifunctional Oxygen Reduction/Evolution Electrocatalyst: Recent Advances and Perspectives. Adv. Energy Mater. 2017, 1700544, 1-21. https://doi.org/10.1002/aenm.201700544.

(9) Liu, J.; Jiao, M.; Lu, L.; Barkholtz, H. M.; Li, Y.; Wang, Y.; Jiang, L.; Wu, Z.; Liu, D.; Zhuang, L.; Ma, C.; Zeng, J.; Zhang, B.; Su, D.; Song, P.; Xing, W.; Xu, W.; Wang, Y.; Jiang, Z.; Sun, G. High Performance Platinum Single Atom Electrocatalyst for Oxygen Reduction Reaction. Nat. Commun. 2017, 8 (1), 15938.

https://doi.org/10.1038/ncomms15938.

(10) Matsubu, J. C.; Zhang, S.; DeRita, L.; Marinkovic, N. S.; Chen, J. G.; Graham, G. W.; Pan, X.; Christopher, P. Adsorbate-Mediated Strong Metal-support Interactions in Oxide-Supported Rh Catalysts. Nat. Chem. 2016, 9 (2), 120-127. https://doi.org/10.1038/nchem.2607.

(11) Xu, M.; He, S.; Chen, H.; Cui, G.; Zheng, L.; Wang, B.; Wei, M. TiO 2-x-Modified Ni Nanocatalyst with Tunable Metal-Support Interaction for Water-Gas Shift Reaction. ACS Catal. 2017, 7 (11), 7600-7609. https://doi.org/10.1021/acscatal.7b01951. 
(12) Cao, M.; Tang, Z.; Liu, Q.; Xu, Y.; Chen, M.; Lin, H.; Li, Y.; Gross, E.; Zhang, Q. The Synergy between Metal Facet and Oxide Support Facet for Enhanced Catalytic Performance: The Case of Pd-TiO 2. Nano Lett. 2016, 16 (8), 5298-5302. https://doi.org/10.1021/acs.nanolett.6b02662.

(13) El-Sawy, A. M.; Mosa, I. M.; Su, D.; Guild, C. J.; Khalid, S.; Joesten, R.; Rusling, J. F.; Suib, S. L. Controlling the Active Sites of Sulfur-Doped Carbon Nanotube-Graphene Nanolobes for Highly Efficient Oxygen Evolution and Reduction Catalysis. Adv. Energy Mater. 2016, 6 (5), 1-12. https://doi.org/10.1002/aenm.201501966.

(14) Ruiz-Camacho, B.; Valenzuela, M. A.; González-Huerta, R. G.; Suarez-Alcantara, K.; Canton, S. E.; Pola-Albores, F. Electrochemical and XAS Investigation of Oxygen Reduction Reaction on Pt-TiO2-C Catalysts. Int. J. Hydrogen Energy 2013, 38 (28), 12648-12656. https://doi.org/10.1016/j.ijhydene.2013.01.002.

(15) Riese, A.; Banham, D.; Ye, S.; Sun, X. Accelerated Stress Testing by Rotating Disk Electrode for Carbon Corrosion in Fuel Cell Catalyst Supports. J. Electrochem. Soc. 2015, 162 (7), F783-F788. https://doi.org/10.1149/2.0911507jes.

(16) Kim, J. H.; Kwon, G.; Lim, H.; Zhu, C.; You, H.; Kim, Y. T. Effects of Transition Metal Doping in Pt/M-TiO2 ( $\mathrm{M}=\mathrm{V}, \mathrm{Cr}$, and $\mathrm{Nb}$ ) on Oxygen Reduction Reaction Activity. J. Power Sources 2016, 320, 188-195. https://doi.org/10.1016/j.jpowsour.2016.04.019.

(17) Jia, C.; Yang, P.; Chen, H.-S.; Wang, J. Template-Free Synthesis of Mesoporous Anatase Titania Hollow Spheres and Their Enhanced Photocatalysis. CrystEngComm 2015, 17 (15), 2940-2948. https://doi.org/10.1039/C4CE02358G. 
1 (18) Ruiz Camacho, B.; Morais, C.; Valenzuela, M. A.; Alonso-Vante, N. Enhancing Oxygen Reduction Reaction Activity and Stability of Platinum via Oxide-Carbon Composites. Catal. Today 2013, 202 (1), 36-43. https://doi.org/10.1016/j.cattod.2012.03.033.

(19) Damato, T. C.; de Oliveira, C. C. S.; Ando, R. A.; Camargo, P. H. C. A Facile Approach to TiO2 Colloidal Spheres Decorated with Au Nanoparticles Displaying Well-Defined Sizes and Uniform Dispersion. Langmuir 2013, 29 (5), 1642-1649.

(20) Cheng, Y.; Guo, J.; Liu, X.; Sun, A.; Xu, G.; Cui, P. Preparation of Uniform Titania Microspheres with Good Electrorheological Performance and Their Size Effect. J. Mater. Chem. 2011, 21 (13), 5051. https://doi.org/10.1039/c0jm03378b.

(21) Nassr, A. B. A. A.; Sinev, I.; Grünert, W.; Bron, M. PtNi Supported on Oxygen Functionalized Carbon Nanotubes: In Depth Structural Characterization and Activity for Methanol Electrooxidation. Appl. Catal. B Environ. 2013, 142-143, 849-860. https://doi.org/10.1016/j.apcatb.2013.06.013.

(22) dos Reis, F. V. E.; Antonin, V. S.; Hammer, P.; Santos, M. C.; Camargo, P. H. C. CarbonSupported TiO2-Au Hybrids as Catalysts for the Electrogeneration of Hydrogen Peroxide: Investigating the Effect of TiO2 Shape. J. Catal. 2015, 326, 100-106.

(23) Liu, C.; Tong, R.; Xu, Z.; Kuang, Q.; Xie, Z.; Zheng, L. Efficiently Enhancing the Photocatalytic Activity of Faceted $\mathrm{TiO}_{2}$ Nanocrystals by Selectively Loading $\alpha-\mathrm{Fe}_{2} \mathrm{O}_{3}$ and Pt Co-Catalysts. RSC Adv. 2016, 6 (35), 29794-29801. https://doi.org/10.1039/C6RA04552A.

(24) Wang, P.; Zhan, S.; Xia, Y.; Ma, S.; Zhou, Q.; Li, Y. The Fundamental Role and 
Mechanism of Reduced Graphene Oxide in RGO/Pt-TiO2 Nanocomposite for HighPerformance Photocatalytic Water Splitting. Appl. Catal. B Environ. 2017, 207, 335346. https://doi.org/10.1016/j.apcatb.2017.02.031.

(25) Lian, Z.; Wang, W.; Li, G.; Tian, F.; Schanze, K. S.; Li, H. Pt-Enhanced Mesoporous Ti3+/TiO2 with Rapid Bulk to Surface Electron Transfer for Photocatalytic Hydrogen Evolution. ACS Appl. Mater. Interfaces 2017, 9 (20), 16959-16966. https://doi.org/10.1021/acsami.6b11494.

(26) Dablemont, C.; Lang, P.; Mangeney, C.; Piquemal, J. Y.; Petkov, V.; Herbst, F.; Viau, G. FTIR and XPS Study of Pt Nanoparticle Functionalization and Interaction with Alumina. Langmuir 2008, 24 (11), 5832-5841. https://doi.org/10.1021/la7028643.

(27) Kobayashi, H.; Teranishi, M.; Negishi, R.; Naya, S.; Tada, H. Reaction Mechanism of the Multiple-Electron Oxygen Reduction Reaction on the Surfaces of Gold and Platinum Nanoparticles Loaded on Titanium(IV) Oxide. J. Phys. Chem. Lett. 2016, 7 (24), 5002-5007. https://doi.org/10.1021/acs.jpclett.6b02026.

(28) Bedolla-Valdez, Z. I.; Verde-Gómez, Y.; Valenzuela-Muñiz, A. M.; Gochi-Ponce, Y.; Oropeza-Guzmán, M. T.; Berhault, G.; Alonso-Núñez, G. Sonochemical Synthesis and Characterization of Pt/CNT, Pt/TiO2, and Pt/CNT/TiO2 Electrocatalysts for Methanol Electro-Oxidation. Electrochim. Acta 2015, 186, 76-84. https://doi.org/10.1016/j.electacta.2015.10.084.

(29) Xia, B. Y.; Wang, B.; Wu, H. Bin; Liu, Z.; Wang, X.; Lou, X. W. Sandwich-Structured TiO2-Pt-graphene Ternary Hybrid Electrocatalysts with High Efficiency and Stability. 
J. Mater. Chem. 2012, 22 (32), 16499. https://doi.org/10.1039/c2jm32816j.

2

(30) Qin, Y.-H.; Li, Y.; Lv, R.-L.; Wang, T.-L.; Wang, W.-G.; Wang, C.-W. Enhanced Methanol Oxidation Activity and Stability of Pt Particles Anchored on Carbon-Doped TiO2 Nanocoating Support. J. Power Sources 2015, 278, 639-644. https://doi.org/10.1016/j.jpowsour.2014.12.096.

(31) Wu, G.; Hu, Y.; Liu, Y.; Zhao, J.; Chen, X.; Whoehling, V.; Plesse, C.; Nguyen, G. T. M.; Vidal, F.; Chen, W. Graphitic Carbon Nitride Nanosheet Electrode-Based HighPerformance Ionic Actuator. Nat. Commun. 2015, 6, 7258. https://doi.org/10.1038/ncomms8258.

(32) Zhou, J.-H.; Sui, Z.-J.; Zhu, J.; Li, P.; Chen, D.; Dai, Y.-C.; Yuan, W.-K. Characterization of Surface Oxygen Complexes on Carbon Nanofibers by TPD, XPS and FT-IR. Carbon N. Y. 2007, 45 (4), 785-796. https://doi.org/10.1016/j.carbon.2006.11.019.

(33) Ganguly, A.; Sharma, S.; Papakonstantinou, P.; Hamilton, J. Probing the Thermal Deoxygenation of Graphene Oxide Using High-Resolution In Situ X-Ray-Based Spectroscopies. J. Phys. Chem. C 2011, 115 (34), 17009-17019. https://doi.org/10.1021/jp203741y.

(34) Assumpção, M. H. M. T.; De Souza, R. F. B.; Rascio, D. C.; Silva, J. C. M.; Calegaro, M. L.; Gaubeur, I.; Paixão, T. R. L. C.; Hammer, P.; Lanza, M. R. V; Santos, M. C. A Comparative Study of the Electrogeneration of Hydrogen Peroxide Using Vulcan and Printex Carbon Supports. Carbon N. Y. 2011, 49 (8), 2842-2851. https://doi.org/10.1016/j.carbon.2011.03.014. 
(35) Assumpção, M. H. M. T.; Moraes, A.; De Souza, R. F. B.; Calegaro, M. L.; Lanza, M. R. V.; Leite, E. R.; Cordeiro, M. A. L.; Hammer, P.; Santos, M. C. Influence of the Preparation Method and the Support on H2O2 Electrogeneration Using Cerium Oxide Nanoparticles. Electrochim. Acta 2013, 111, 339-343. https://doi.org/10.1016/j.electacta.2013.07.187.

(36) Salgado, J. R. C.; Paganin, V. A.; Gonzalez, E. R.; Montemor, M. F.; Tacchini, I.; Ansón, A.; Salvador, M. A.; Ferreira, P.; Figueiredo, F. M. L.; Ferreira, M. G. S. Characterization and Performance Evaluation of Pt-Ru Electrocatalysts Supported on Different Carbon Materials for Direct Methanol Fuel Cells. Int. J. Hydrogen Energy 2013, 38 (2), 910920. https://doi.org/10.1016/j.ijhydene.2012.10.079.

(37) Lewera, A.; Timperman, L.; Roguska, A.; Alonso-Vante, N. Metal-Support Interactions between Nanosized Pt and Metal Oxides (WO 3 and TiO 2 ) Studied Using X-Ray Photoelectron Spectroscopy. J. Phys. Chem. C 2011, 115 (41), 20153-20159. https://doi.org/10.1021/jp2068446.

(38) Ma, J.; Habrioux, A.; Morais, C.; Lewera, A.; Vogel, W.; Verde-Gómez, Y.; RamosSanchez, G.; Balbuena, P. B.; Alonso-Vante, N. Spectroelectrochemical Probing of the Strong Interaction between Platinum Nanoparticles and Graphitic Domains of Carbon. ACS Catal. 2013, 3 (9), 1940-1950. https://doi.org/10.1021/cs4003222.

(39) López-Cudero, A.; Solla-Gullón, J.; Herrero, E.; Aldaz, A.; Feliu, J. M. CO Electrooxidation on Carbon Supported Platinum Nanoparticles: Effect of Aggregation. J. Electroanal. Chem. 2010, 644 (2), 117-126. 
https://doi.org/10.1016/j.jelechem.2009.06.016.

(40) Zheng, Y.; Chen, H.; Dai, Y.; Zhang, N.; Zhao, W.; Wang, S.; Lou, Y.; Li, Y.; Sun, Y. Preparation and Characterization of $\mathrm{Pt} / \mathrm{TiO} 2$ Nanofibers Catalysts for Methanol Electro-Oxidation. Electrochim. Acta 2015, 178, 74-79.

https://doi.org/10.1016/j.electacta.2015.07.177.

(41) Lima, F. H. B.; Lizcano-Valbuena, W. H.; Teixeira-Neto, E.; Nart, F. C.; Gonzalez, E. R.;

Ticianelli, E. A. Pt-Co/C Nanoparticles as Electrocatalysts for Oxygen Reduction in H2SO4 and $\mathrm{H} 2 \mathrm{SO} 4 / \mathrm{CH} 3 \mathrm{OH}$ Electrolytes. Electrochim. Acta 2006, 52 (2), 385-393. https://doi.org/10.1016/j.electacta.2006.05.019.

(42) Ruiz-Camacho, B.; Martínez-Álvarez, O.; Rodríguez-Santoyo, H. H.; Granados-Alejo, V. $\mathrm{Pt} / \mathrm{C}$ and Pt/TiO2-C Electrocatalysts Prepared by Chemical Vapor Deposition with High Tolerance to Alcohols in Oxygen Reduction Reaction. J. Electroanal. Chem. 2014, 725, 19-24. https://doi.org/10.1016/j.jelechem.2014.04.019.

(43) Ferrero, G. A.; Preuss, K.; Marinovic, A.; Jorge, A. B.; Mansor, N.; Brett, D. J. L.; Fuertes, A. B.; Sevilla, M.; Titirici, M.-M. Fe-N-Doped Carbon Capsules with Outstanding Electrochemical Performance and Stability for the Oxygen Reduction Reaction in Both Acid and Alkaline Conditions. ACS Nano 2016, 10 (6), 5922-5932. https://doi.org/10.1021/acsnano.6b01247.

(44) Shih, Y.-H.; Sagar, G. V.; Lin, S. D. Effect of Electrode Pt Loading on the Oxygen Reduction Reaction Evaluated by Rotating Disk Electrode and Its Implication on the Reaction Kinetics. J. Phys. Chem. C 2008, 112 (1), 123-130. 
https://doi.org/10.1021/jp071807h.

2

(45) Santos, L. G. R. A.; Freitas, K. S.; Ticianelli, E. A. Heat Treatment Effect of Pt-V/C and $\mathrm{Pt} / \mathrm{C}$ on the Kinetics of the Oxygen Reduction Reaction in Acid Media. Electrochim. Acta 2009, 54 (22), 5246-5251. https://doi.org/10.1016/j.electacta.2009.03.078.

(46) Demarconnay, L.; Coutanceau, C.; Léger, J.-M. Study of the Oxygen Electroreduction at Nanostructured PtBi Catalysts in Alkaline Medium. Electrochim. Acta 2008, 53 (8), 3232-3241. https://doi.org/10.1016/j.electacta.2007.07.006.

(47) Zhou, R.; Zheng, Y.; Jaroniec, M.; Qiao, S.-Z. Determination of the Electron Transfer Number for the Oxygen Reduction Reaction: From Theory to Experiment. ACS Catal. 2016, 6 (7), 4720-4728. https://doi.org/10.1021/acscatal.6b01581.

(48) Tiido, K.; Alexeyeva, N.; Couillard, M.; Bock, C.; MacDougall, B. R.; Tammeveski, K. Graphene-TiO2 Composite Supported Pt Electrocatalyst for Oxygen Reduction Reaction. Electrochim. Acta 2013, 107, 509-517. https://doi.org/10.1016/j.electacta.2013.05.155.

(49) Tammeveski, K. The Reduction of Oxygen on Pt-TiO2 Coated Ti Electrodes in Alkaline Solution. J. Electrochem. Soc. 1999, 146 (2), 669. https://doi.org/10.1149/1.1391660.

(50) Shinagawa, T.; Garcia-Esparza, A. T.; Takanabe, K. Insight on Tafel Slopes from a Microkinetic Analysis of Aqueous Electrocatalysis for Energy Conversion. Sci. Rep. 2015, 5 (August), 1-21. https://doi.org/10.1038/srep13801.

(51) Elezovic, N. R.; Babic, B. M.; Radmilovic, V. R.; Vracar, L. M.; Krstajic, N. V. NbTiO2supported Platinum Nanocatalyst for Oxygen Reduction Reaction in Alkaline 
Solutions. Electrochim. Acta 2011, 56 (25), 9020-9026. https://doi.org/10.1016/j.electacta.2011.04.075.

(52) Li, L.; Wei, Z.; Zhang, Y.; Qi, X.; Xia, M.; Zhang, J.; Shao, Z.; Sun, C. DFT Study of Difference Caused by Catalyst Supports in Pt and Pd Catalysis of Oxygen Reduction Reaction. Sci. China Ser. B Chem. 2009, 52 (5), 571-578. https://doi.org/10.1007/s11426-009-0006-2.

7 (53) Huang, K.; Sasaki, K.; Adzic, R. R.; Xing, Y. Increasing Pt Oxygen Reduction Reaction Activity and Durability with a Carbon-Doped TiO2 Nanocoating Catalyst Support. J. Mater. Chem. 2012, 22 (33), 16824. https://doi.org/10.1039/c2jm32234j.

(54) Shanmugam, S.; Gedanken, A. Carbon-Coated Anatase TiO2 Nanocomposite as a High-Performance Electrocatalyst Support. Small 2007, 3 (7), 1189-1193. https://doi.org/10.1002/smll.200600636. 

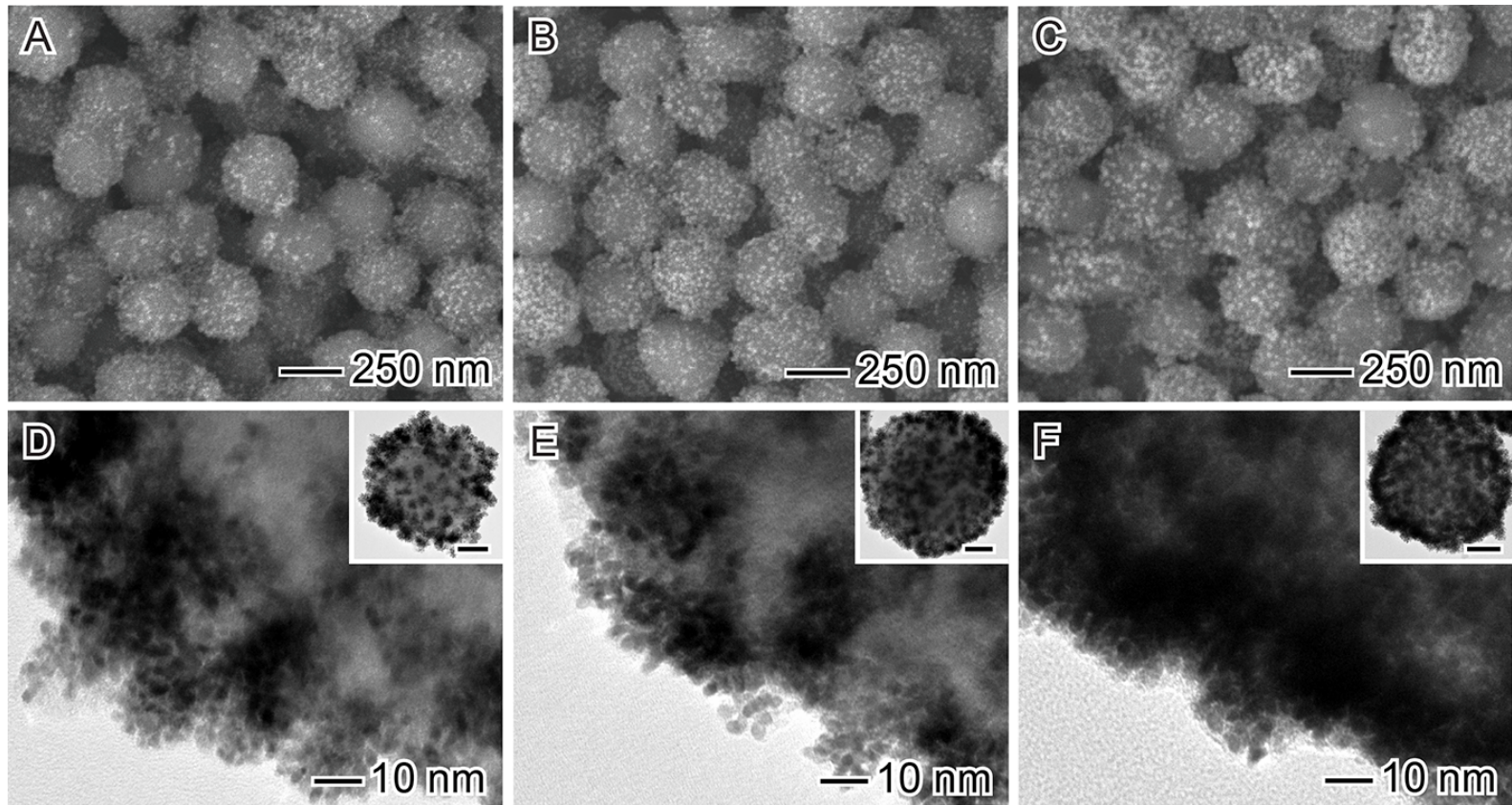

2 Figure 1. SEM (A-C) and TEM (D-F) images of Pt NPs supported at the surface of $\mathrm{TiO}_{2}$ colloidal

3 spheres $\left(\mathrm{Pt} / \mathrm{TiO}_{2}\right)$ after one $(\mathrm{A}, \mathrm{D})$, two $(\mathrm{B}, \mathrm{E})$, and three $(\mathrm{C}, \mathrm{F})$ deposition steps. The scale bars 4 in the insets correspond to $50 \mathrm{~nm}$. 
A

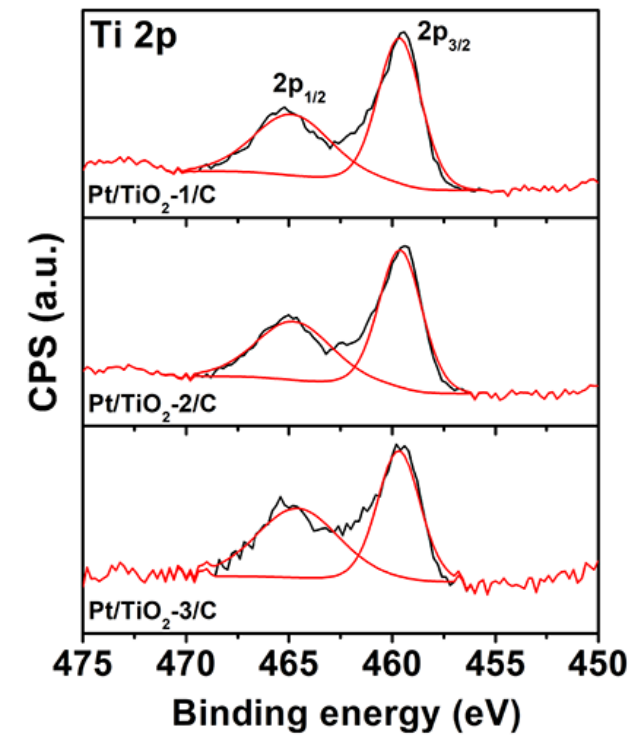

C

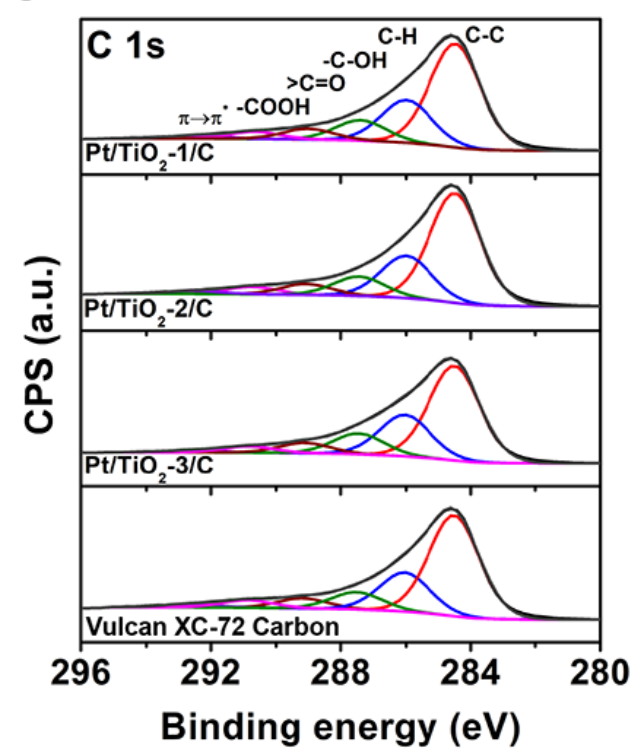

B

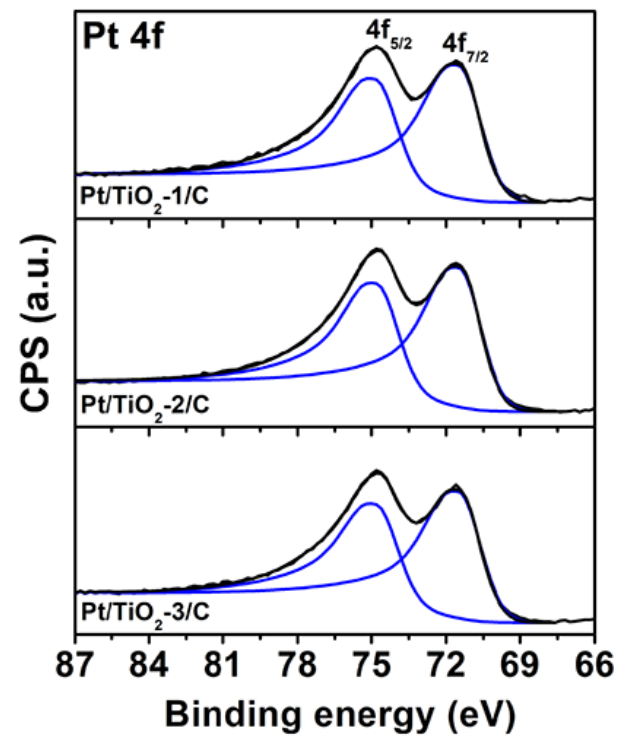

D

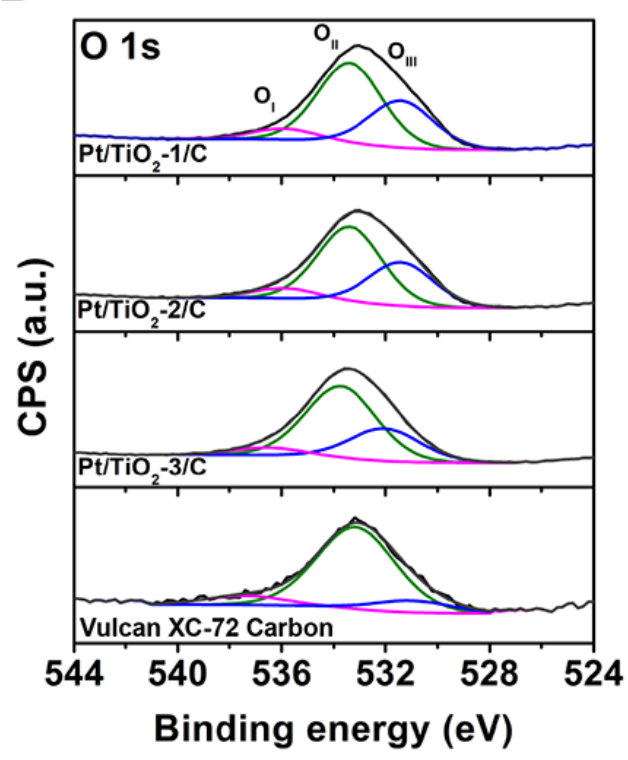

2 Figure 2. Deconvoluted X-ray photoelectron spectra (XPS) of the Ti $2 p(A), \operatorname{Pt} 4 f(B), C$ 1s (C),

3 and $\mathrm{O} 1 \mathrm{~s}$ (D) core levels for $\mathrm{Pt} / \mathrm{TiO}_{2}-1 / \mathrm{C}, \mathrm{Pt} / \mathrm{TiO}_{2}-2 / \mathrm{C}, \mathrm{Pt} / \mathrm{TiO}_{2}-3 / \mathrm{C}$, Vulcan XC-72 carbon (top to 4 bottom traces, respectively). 

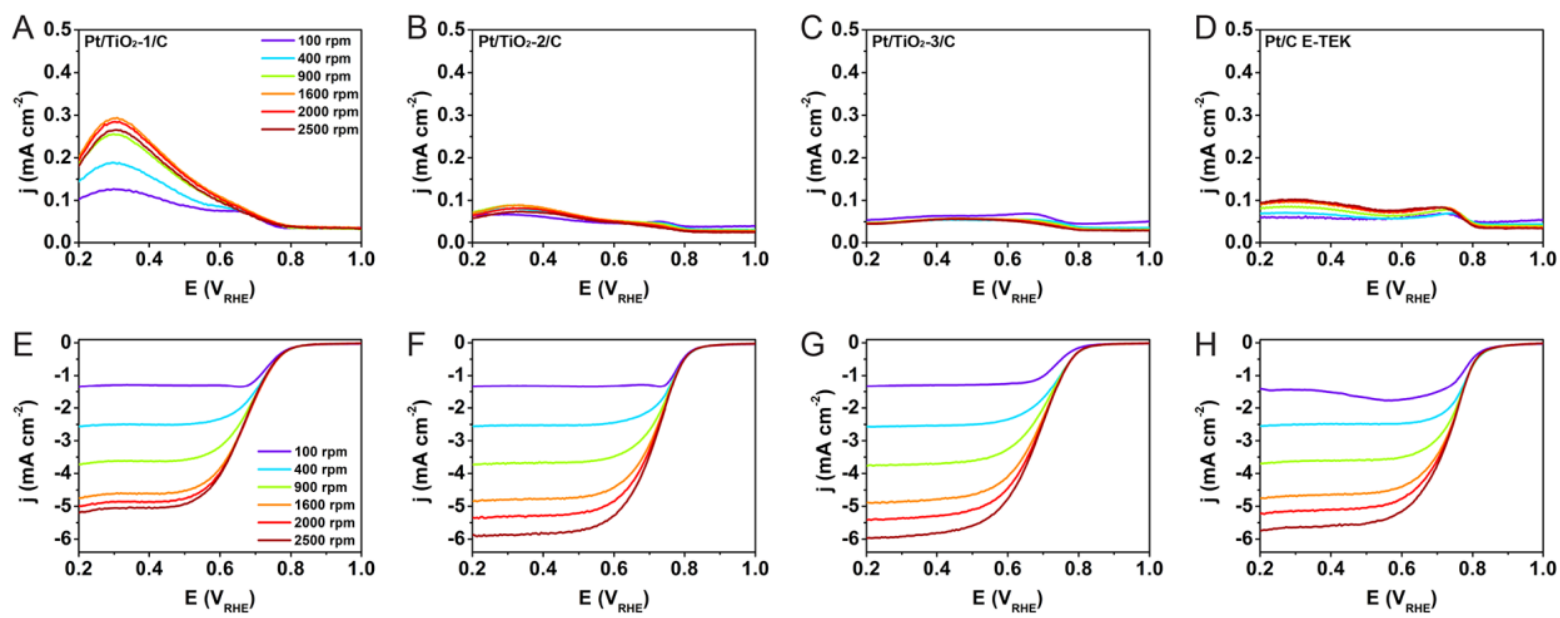

2 Figure 3. Rotating ring (A-D) and rotating disk $(E-H)$ voltammograms for the ORR employing 3 $\mathrm{Pt} / \mathrm{TiO}_{2}-1 / \mathrm{C}(\mathrm{A}, \mathrm{E}), \mathrm{Pt} / \mathrm{TiO}_{2}-2 / \mathrm{C}$ $(\mathrm{B}, \mathrm{F}), \mathrm{Pt} / \mathrm{TiO}_{2}-3 / \mathrm{C}$ (C, G), and Pt/C E-TEK $(D, H)$ as electrocatalysts. These experiments were performed in $\mathrm{O}_{2}$ saturated $0.5 \mathrm{~mol} \mathrm{~L}^{-1} \mathrm{H}_{2} \mathrm{SO}_{4}$ with a sweep rate of $10 \mathrm{mVs}^{-1}$ at different rotation rates (as indicated in the insets) and $273 \mathrm{~K}$. 


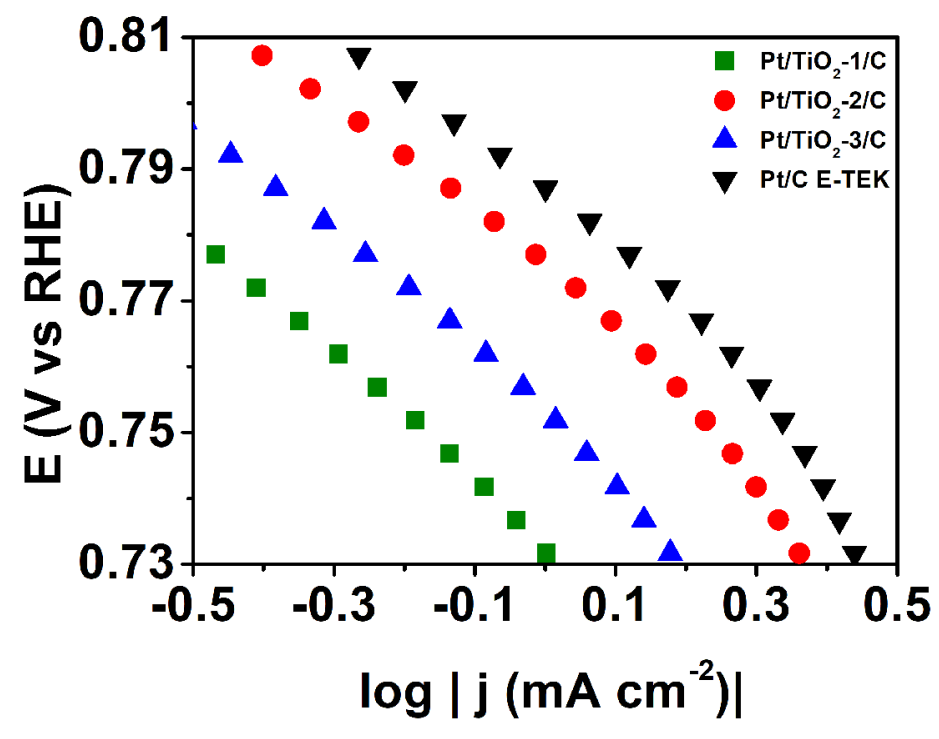

2 Figure 4. Tafel plots for $\mathrm{Pt} / \mathrm{TiO}_{2}-1 / \mathrm{C}$ (green trace), $\mathrm{Pt} / \mathrm{TiO}_{2}-2 / \mathrm{C}$ (red trace), $\mathrm{Pt} / \mathrm{TiO}_{2}-3 / \mathrm{C}$ (blue 3 trace) and Pt/C E-TEK (black trace). The data was normalized by the geometric area of the 4 electrode and calculated from their corresponding rotating disk electrode values at $1600 \mathrm{rpm}$. 

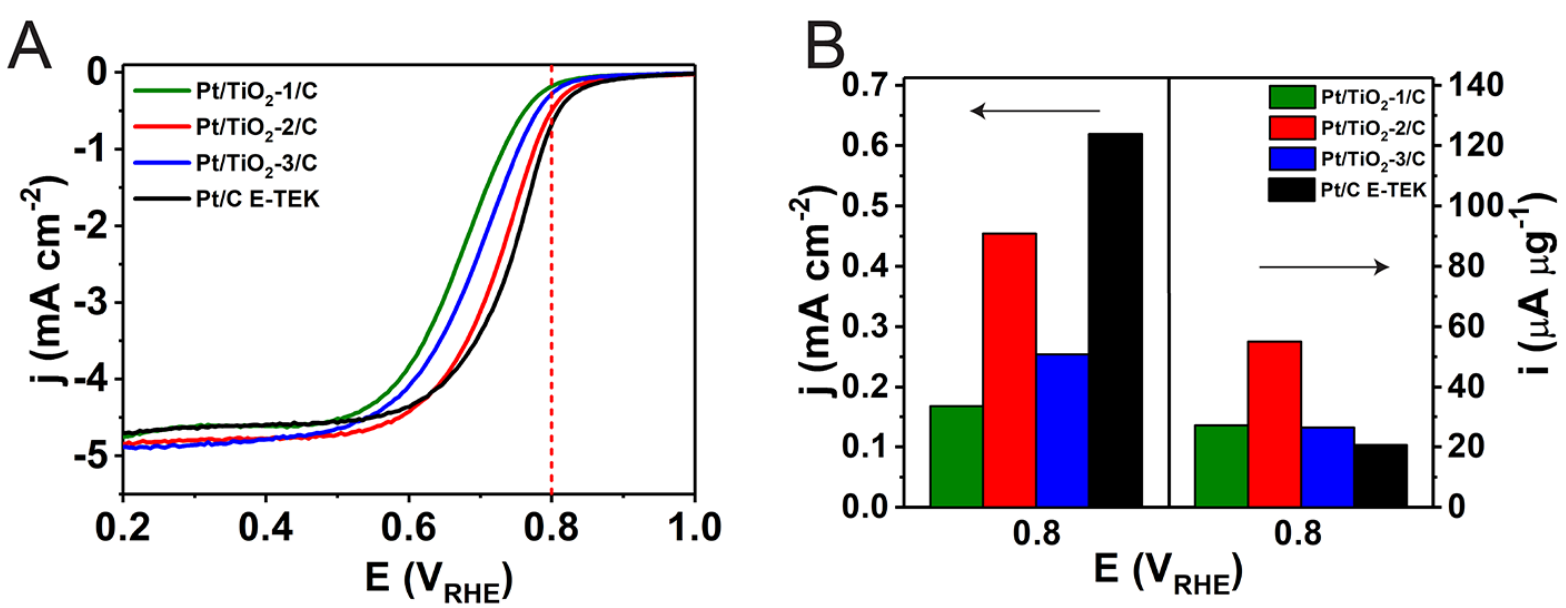

Figure 5. (A) Comparison of rotating disk linear scanning voltammetry for the ORR employing $\mathrm{Pt} / \mathrm{TiO}_{2}-1 / \mathrm{C}$ (green trace), $\mathrm{Pt} / \mathrm{TiO}_{2}-2 / \mathrm{C}$ (red trace), $\mathrm{Pt} / \mathrm{TiO}_{2}-3 / \mathrm{C}$ (blue trace) and $\mathrm{Pt} / \mathrm{C} \mathrm{E}-\mathrm{TEK}$ (black trace) as electrocatalysts. The ORR was measured in $\mathrm{O}_{2}$ saturated $0.5 \mathrm{~mol} \mathrm{~L}^{-1} \mathrm{H}_{2} \mathrm{SO}_{4}$ solution at a rotation rate of $1600 \mathrm{rpm}$ and $T=273 \mathrm{~K}$. (B) Left panel: current densities at $0.8 \mathrm{~V}$ vs RHE for the materials shown in (A); Right panel: current densities divided by the Pt mass at $0.8 \mathrm{~V}$ vs RHE for the materials shown in $(A)$. 

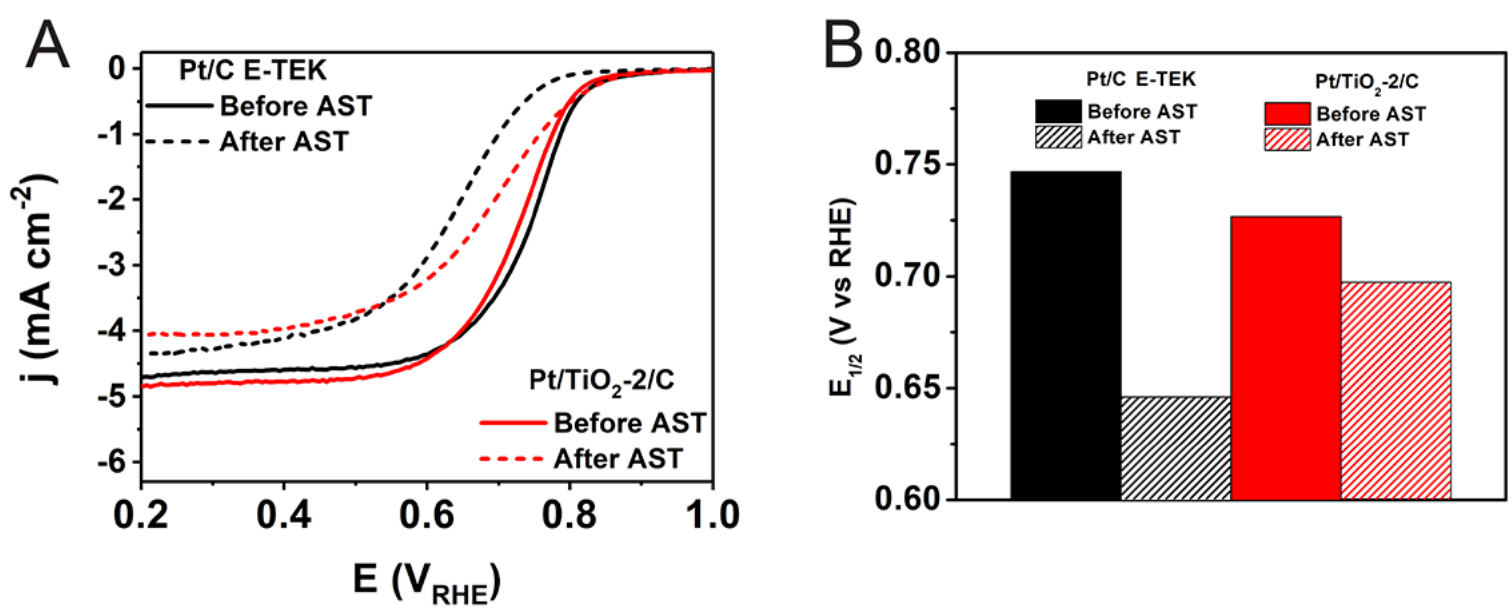

Figure 6. (A) Comparison of ORR polarization curves for $\mathrm{Pt} / \mathrm{TiO}_{2}-2 / \mathrm{C}$ (red trace) and $\mathrm{Pt} / \mathrm{C}$ E-TEK (black trace) before (solid line) and after (dashed line) accelerated stress tests. The AST were performed using a $100 \mathrm{mV} \mathrm{s}^{-1}$ scanning rate and 1000 voltammetric cycles from 0.01 to 1.01 V vs RHE. ORR was performed in $\mathrm{O}_{2}$ saturated $0.5 \mathrm{~mol} \mathrm{~L}^{-1} \mathrm{H}_{2} \mathrm{SO}_{4}$ solution at a rotation rate of $1600 \mathrm{rpm}$. (B) Half-wave potential for each sample before and after the accelerated stress test. $\mathrm{T}=273 \mathrm{~K}$. 
Table 1. Binding energies and surface percentages measured by XPS.

\begin{tabular}{|c|c|c|c|c|c|}
\hline \multirow{3}{*}{ Material } & \multicolumn{5}{|c|}{ Binding energy (eV) } \\
\hline & \multirow{2}{*}{ Pt $4 f_{7 / 2}$} & \multirow{2}{*}{ Ti $2 p_{3 / 2}$} & \multicolumn{3}{|c|}{$01 \mathrm{~s}$} \\
\hline & & & $\mathbf{O}_{1}$ & $\mathbf{O}_{\| 1}$ & $\mathbf{O}_{\text {III }}$ \\
\hline Vulcan XC-72 & n.d. & n.d. & $530.9(11)^{*}$ & $533.2(80)$ & $536.8(9)$ \\
\hline $\mathrm{Pt} / \mathrm{TiO}_{2}-1 / \mathrm{C}$ & 71.5 & 459.6 & $531.4(34)$ & $533.4(58)$ & $536.0(8)$ \\
\hline $\mathrm{Pt} / \mathrm{TiO}_{2}-2 / \mathrm{C}$ & 71.5 & 459.6 & $531.4(32)$ & $533.3(60)$ & $535.9(8)$ \\
\hline $\mathrm{Pt} / \mathrm{TiO}_{2}-3 / \mathrm{C}$ & 71.5 & 459.7 & $531.7(28)$ & $533.7(65)$ & $536.5(7)$ \\
\hline
\end{tabular}

*Species surface percentage 
Table 2. Binding energies, surface percentages, and oxygenated carbon/carbon ratios measured by XPS.

\begin{tabular}{c|c|c|c|c|c|c|c}
\hline \hline \multirow{2}{*}{ Material } & \multicolumn{9}{|c|}{ Binding energy C 1s (eV) } & \multicolumn{2}{c}{$\begin{array}{c}\text { Intensity } \\
\text { (\%) }\end{array}$} \\
\cline { 2 - 9 } & Peak I C-C & $\begin{array}{c}\text { Peak II C-H } \\
\text { (defects) }\end{array}$ & $\begin{array}{c}\text { Peak III -C- } \\
\text { OH }\end{array}$ & $\begin{array}{c}\text { Peak IV } \\
>C=0\end{array}$ & $\begin{array}{c}\text { Peak V - } \\
\text { COOH }\end{array}$ & $\begin{array}{c}\text { Peak VI } \\
\pi \rightarrow \pi^{*}\end{array}$ & Ioxy/Ic** \\
\hline Vulcan XC-72 & $284.5(57) *$ & $286.0(21)$ & $287.5(10)$ & $289.2(6)$ & $290.8(4)$ & $292.8(2)$ & 19 \\
\hline Pt/TiO 2-1/C & $284.5(55)$ & $286.0(23)$ & $287.4(10)$ & $289.0(6)$ & $290.6(4)$ & $292.4(2)$ & 26 \\
\hline Pt/TiO 2-2/C & $284.5(57)$ & $286.0(22)$ & $287.4(10)$ & $289.0(6)$ & $290.8(4)$ & $292.5(1)$ & 25 \\
\hline Pt/TiO $2-3 / C$ & $284.5(54)$ & $286.0(24)$ & $287.5(11)$ & $289.1(6)$ & $290.8(4)$ & $292.5(1)$ & 27 \\
\hline \hline
\end{tabular}

* Species surface percentage

${ }^{* *}$ Intensity of three oxygen-containing functional groups (peaks III-V) in $\%$ of total C 1 s area. 
Table 3. Summary of the RRDE data obtained for the ORR employing $\mathrm{Pt} / \mathrm{TiO}_{2}-1 / \mathrm{C}, \mathrm{Pt} / \mathrm{TiO}_{2}-2 / \mathrm{C}$, $\mathrm{Pt} / \mathrm{TiO}_{2}-3 / \mathrm{C}$, and Pt/C-ETEK as electrocatalysts. $n$ refers to the number of exchanged electrons and $p$ the water proportion efficiency based on the ring and disk currents. ${ }^{47}$

\begin{tabular}{c|c|c|c|c|c|c|c|c}
\hline \hline \multirow{2}{*}{ E vs RHE } & \multicolumn{2}{|c|}{$\mathrm{Pt} / \mathrm{TiO}_{2}-\mathbf{1} / \mathbf{C}$} & \multicolumn{2}{c|}{$\mathrm{Pt} / \mathrm{TiO}_{2}-\mathbf{2} / \mathbf{C}$} & \multicolumn{2}{c|}{$\mathrm{Pt} / \mathrm{TiO}_{2}-\mathbf{3} / \mathbf{C}$} & \multicolumn{2}{c}{$\mathrm{Pt} / \mathrm{C}-\mathrm{ETEK}$} \\
\cline { 2 - 10 } & $n$ & $p\left(\mathrm{H}_{2} \mathrm{O}\right) \%$ & $n$ & $p\left(\mathrm{H}_{2} \mathrm{O}\right) \%$ & $n$ & $p\left(\mathrm{H}_{2} \mathrm{O}\right) \%$ & $n$ & $p\left(\mathrm{H}_{2} \mathrm{O}\right) \%$ \\
\hline $\mathbf{0 . 6 0}$ & 3.94 & 97.1 & 3.98 & 98.8 & 3.97 & 98.3 & 3.97 & 98.6 \\
\hline $\mathbf{0 . 5 0}$ & 3.93 & 96.4 & 3.97 & 98.6 & 3.97 & 98.3 & 3.97 & 98.7 \\
\hline $\mathbf{0 . 4 0}$ & 3.90 & 94.9 & 3.97 & 98.3 & 3.96 & 98.1 & 3.98 & 98.8 \\
\hline $\mathbf{0 . 3 0}$ & 3.87 & 93.7 & 3.96 & 98.2 & 3.96 & 97.9 & 3.98 & 99.0 \\
\hline $\mathbf{0 . 2 0}$ & 3.92 & 95.8 & 3.97 & 98.5 & 3.96 & 98.0 & 3.98 & 99.0 \\
\hline Mean & 3.91 & 95.6 & 3.97 & 98.5 & 3.96 & 98.1 & 3.98 & 98.8 \\
\hline \hline
\end{tabular}




\section{Table of Contents}

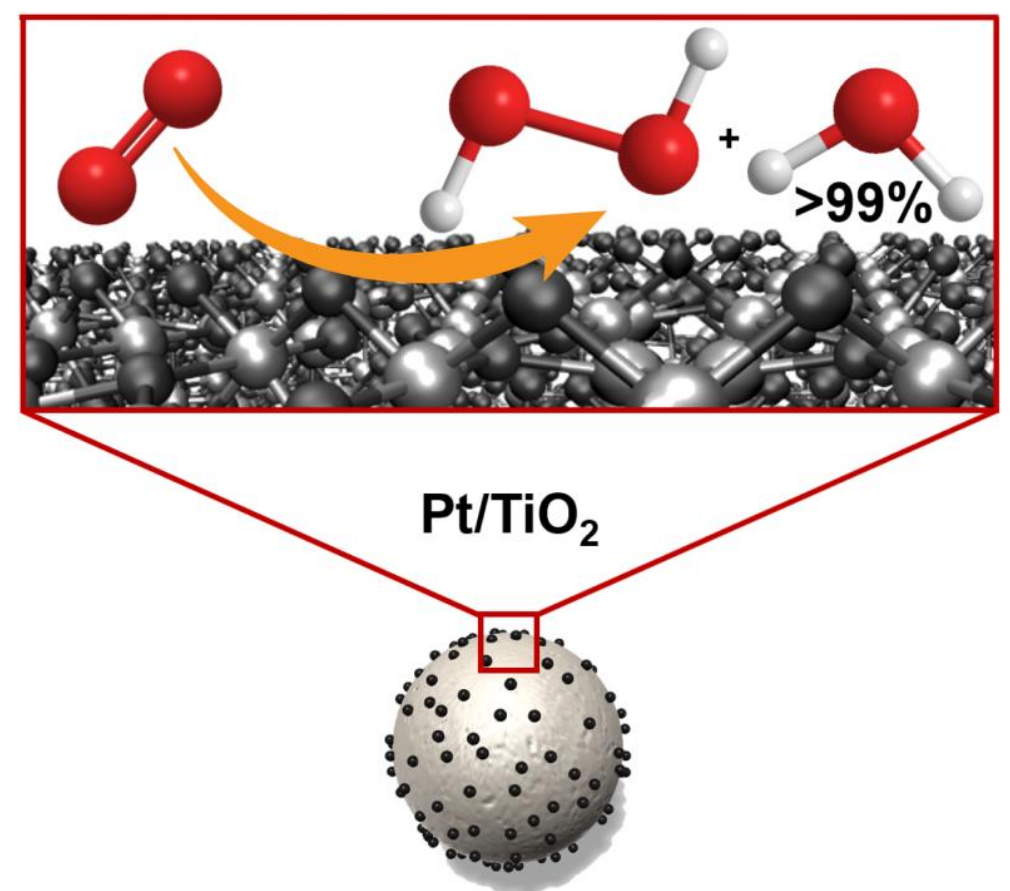

